\title{
Séjour mouvementé d'un révolutionnaire italien à Toronto et à Québec
}

\section{Robert Sylvain}

Volume 13, numéro 2, septembre 1959

URI : https://id.erudit.org/iderudit/301967ar

DOI : https://doi.org/10.7202/301967ar

Aller au sommaire du numéro

Éditeur(s)

Institut d'histoire de l'Amérique française

ISSN

0035-2357 (imprimé)

1492-1383 (numérique)

Découvrir la revue

Citer cet article

Sylvain, R. (1959). Séjour mouvementé d'un révolutionnaire italien à Toronto et à Québec. Revue d'histoire de l'Amérique française, 13(2), 183-229.

https://doi.org/10.7202/301967ar d'utilisation que vous pouvez consulter en ligne.

https://apropos.erudit.org/fr/usagers/politique-dutilisation/ 


\section{SÉJOUR MOUVEMENTÉ D'UN RÉVOLUTIONNAIRE ITALIEN À TORONTO ET À QUÉBEC *}

Quand Alessandro Gavazzi, escorté de son secrétaire, un ex-religieux servite italien du nom de Paoli qui, vivant en exil à Boston, lui avait offert ses services ${ }^{1}$, débarqua à Toronto le

* J'ai rédigé les pages qui suivent après avoir soumis à un recoupement aussi rigoureux que possible les renseignements, inutilisés jusqu'ici, qui se dégagent de trois sources essentielles: une lettre circonstanciée qu'Alessandro Gavazzi écrivit à Québec deux jours après l'échauffourée qui avait failli lui coûter la vie, et adressée à son ami new-yorkais Secchi de Casali, qui la fit paraître dans son journal L'Eco d'Italia, le 11 juin 1853; les dépositions qui furent recueillies dans le Rapport des commissaires nommés pour faire une enquête sur la conduite des autorités de police lors de l'émeute de l'église (sic) Chalmers, le 6 juin 1853, avec les minutes des procédés (sic) et des témoignages rendus devant la dite commission, Québec, 1854, in-8 de 128 pp.: c'est la version française du même ouvrage qui parut également à Québec la même année; enfin le récit extrêmement vivant de Gavazzi dans ses Memorie autobiografiche. - Ces Memorie se composent de 54 cahiers manuscrits $23 \times 30 \mathrm{~cm}$, comprenant 1086 pages numérotées, en raison des exigences archivistiques, de 091008 à 092094 . L'ex-barnabite les rédigea probablement, étant donnée la mention qu'il fait du ministère Crispi, du mois d'août 1887 au 9 janvier 1889, date de sa mort soudaine. Cette autobiographie s'interrompt à l'année 1868. Elle se divise en quatre parties: la première, sans titre, va de l'entrée au noviciat napolitain des barnabites, 1825 à 1846 , l'année de l'avènement de Pie IX; la deuxième, intitulée Patria, comprend les années 1847, 1848 et 1849; la troisième, sous le titre Esiglio, couvre la décennie 1849-1859; la dernière, Ritorno, va de 1859 à 1868. Ces pages d'un Romagnol, qui se trouvaient dans les archives personnelles de Mussolini, un autre Romagnol, furent déposées par la Commission des Alliés pour la récupération des documents, en 1947, aux Archives centrales de Rome (Archivio Centrale dello Stato, Palazzo della Sapienza), où elles font partie, depuis 1950, de la Mostra didascalica organisée par le professeur Armando Lodolini, qui, dans son travail: Contributo alla biografia del Padre Alessandro Gavazzi, paru dans la Rassegna storica del Risorgimento, XLIII (1956), pp. 434-448, indique la portée historique de ce «précieux manuscrit». Un autre chercheur, M. Giorgio Cencetti, l'avait déjà étudié et en avait publié quelques extraits intéressants: Alcune pagine dell'autobiografia del P. Alessandro Gavazzi, dans Atti e Memorie della deputazione di storia patria per le Provincie di Romagna, nuova serie, I (1948): 153-173.

1 Gavazzi, Memorie, 091781. 
31 mai $1853^{2}$, il se retrouvait dans une atmosphère qui lui était familière. Il connaissait fort bien l'Angleterre, l'Écosse et l'Irlande pour s'être créé des relations et avoir discouru, pendant un an et demi, dans les principales villes. Or Toronto, au milieu $\mathrm{du}$ siècle dernier, était comme le résumé ethnique du RoyaumeUni.

En effet, sur une population de 30.775 personnes, comme l'indiquait le recensement de 1851 , plus de 28.000 se rattachaient par leurs origines raciales à la Grande-Bretagne et à l'Irlande. L'élément irlandais comprenait, à lui seul, environ 35 pour cent de la population totale ${ }^{3}$ : Irlandais du Nord comme Irlandais du Sud avaient transporté à Toronto leurs antagonismes séculaires, reconstituant sur les bords du lac Ontario un nouveau Belfast, que le chauvinisme anglais et écossais eût souhaité, pour sa part, pouvoir comparer à Londres ou à Edimbourg.

Communauté de race et de sentiments britanniques, Toronto avait encore comme caractéristique essentielle un torysme invétéré, qui était fait de loyalisme à la Couronne et à l'Empire, d'antipathie à l'endroit des États-Unis, d'attachement au statu quo économique et politique comme aux privilèges des classes possédantes. De haine du catholicisme aussi ${ }^{4}$, haine qui s'alimentait aux sentiments antipapistes d'un protestantisme que l'« agression papale » venait de rendre encore plus combatif, et à l'orangisme qui faisait partie du bagage idéologique de l'émigrant de l'Ulster ${ }^{5}$.

Gavazzi, qui éprouvait une vive admiration pour la «supériorité des Anglo-Saxons » dans le domaine économique, pouvait également contempler une ville en plein développement commercial, sinon manufacturier. Le creusement de canaux le long du

2 Globe, June 2, 1853. - Il venait de New York. Cf. Robert Sylvain, Alessandro Gavazzi à New York: un agitateur parmi d'autres agitateurs, dans la Revue d'histoire de l'Amérique française, XI (juin 1957), 92. Il ne manqua pas en route d'aller payer son tribut d'admiration au Naigara (sic), dont la majesté le stupéfia au point qu'il en demeura «stordito», puis il gagna Toronto sur un «navicello abbastanza primitivo» (Memorie, 091777-091779).

3 D.C. Masters, The Rise of Toronto, 1850-1890 (Toronto, 1947), 21.

4 Masters, ibid., 27.

5 Dans le corps législatif de 1857, il n'y avait pas moins de 20 représentants du Haut-Canada sur 65 , qui étaient soit orangistes, soit liés aux intérêts orangistes. (Arthur R. M. Lower, Canadians in the making. A Social History of Canada (Toronto, 1958), 266). 
Saint-Laurent, la réciprocité mercantile qu'un traité allait bientôt ratifier, le chemin de fer, bien qu'il ne fût qu'à ses débuts, favorisaient, avec le Nord-Est des États-Unis, surtout avec New York, des transactions qui s'intensifiaient d'année en année ${ }^{6}$.

Mais ce qui plut sans doute encore davantage à l'adversaire du catholicisme qu'était devenu l'ex-barnabite, ce fut de se retrouver dans une ville en grande majorité protestante. Les anglicans dominaient de beaucoup avec 11.577 adhérents. Ils l'emportaient encore socialement et politiquement, car ils se recrutaient surtout dans l'élite de la ville qui se rattachait au célèbre Family Compact.

Les presbytériens venaient après les anglicans avec 4.544 fidèles. En 1844, 83 membres s'étaient séparés de St. Andrew's lors de la Disruption of the Church of Scotland pour se joindre aux presbytériens irlandais et former Knox Church, rue Richmond. Ce temple, détruit par le feu en 1847, avait été remplacé par un autre édifice construit rue Queen, à proximité de la rue Yonge. Ainsi en 1850, pour une population en grande partie écossaise, dont le presbytérianisme était vigoureux, il y avait trois temples: St. Andrew's, Knox Church et celui de Bay Street.

Les méthodistes ajoutaient leur note d'austère moralisme à la communauté torontoise. Ils constituaient un groupe de 4.123 personnes. Les baptistes ne comptaient que 943 membres; les autres sectes totalisaient 1.643 individus.

Le protestantisme à Toronto, au milieu du siècle dernier, comprenait donc presque 23.000 adhérents; en revanche, les catholiques ne comptaient que 7.940 fidèles, ce qui ne représentait pas même le tiers de la population ${ }^{7}$. Mais ils témoignaient d'une belle vitalité, symbolisée par la cathédrale Saint-Michel, inaugurée en 1848, qui attirait l'attention des étrangers au même titre que St. Lawrence Hall et Osgoode Hall ${ }^{8}$. Leur chef, l'énergique Mgr François-Marie de Charbonnel, luttait sans trève pour la cause des écoles séparées. C'était plus que suffisant pour attirer l'attention sur eux des sectes protestantes et soulever une

6 Masters, op. cit., 13-15.

7 Masters, ibid., 33-38.

8 Masters, ibid., 12. 
opposition acharnée. Même les propensions romanisantes du tractarianisme ne trouvaient pas grâce aux yeux de certains fanatiques ${ }^{9}$.

Deux journaux surtout, à Toronto, se distinguaient par leur sectarisme: le North American, organe des Clear Grits, mais davantage encore le Globe, qui d'emblée, à sa fondation, avait trouvé dans le torysme torontois l'atmosphère propice à l'expression des sentiments anticatholiques de son fondateur et rédacteur en chef.

C'est le Globe qui avait préparé les voies à Gavazzi ${ }^{10}$. Dès septembre 1851, il avait attiré l'attention sur les prédications itinérantes de l'apostolat en Écosse, à Glasgow et à Edimbourg '" Quand il débarqua à New-York, le même journal ne laissa pas de signaler à ses lecteurs l'«accueil chaleureux» que «cet homme éloquent» avait reçu au Broadway Tabernacle, puis de reproduire, pour donner un avant-goût de ces diatribes, le discours sur l'Inquisition prononcé au Metropolitan Hall ${ }^{12}$.

Enfin il ne se tint pas de joie lorsqu'il put annoncer la visite de Gavazzi à Toronto même. Après avoir indiqué que l'Italien donnerait deux conférences aux moments et aux endroits qui seraient opportuns et dont il ne manquerait pas d'aviser ses lecteurs, le journal célébrait le patriote qui avait rallié le mouvement révolutionnaire de 1848 et qui, «par ses éloquents appels », avait suscité ces « hauts faits d'armes qui, n'eût été l'intervention française, eussent délivré son pays du joug papal ». Réduit à s'enfuir en Angleterre après la prise de Rome, il avait tourné son activité contre le catholicisme. Ses conférences, "pourvues des arguments les plus forts contre Rome et le romanisme»,

${ }^{9}$ Cf. Franklin Arthur Walker, Protestant Reaction in Upper Canada to the «Popish Threat», dans The Canadian Catholic Historical Association, (Report 1951), 99.

10 Qui reconnaît les services que George Brown lui rendit par son journal (Memorie, 091782).

11 Globe, September 18, 20, 1851.

12 Globe, April 5, 1853. 
étaient d'autant plus persuasives que l'orateur avait « vu l'Église papale en son centre et, la connaissant parfaitement, il (savait) où frapper ». Aussi le journaliste était-il assuré que Toronto le recevrait « avec le plus vif enthousiasme ${ }^{13}$.

Le rédacteur du Globe ne se trompait pas sur les sentiments de ses concitoyens. Le 31 mai $^{14}$, une foule nombreuse, avide d'entendre le célèbre Italien, se réunissait dans St. Lawrence Hall, édifice public terminé deux ans plus tôt, qui était en quelque sorte le centre de l'activité intellectuelle de la ville: concerts, conférences, réunions de tous genres y avaient lieu ${ }^{15}$.

«Bien avant huit heures, écrivait le journaliste du Globe, il n'y avait plus dans St. Lawrence Hall de place disponible, et dès le début de la conférence des personnes avaient envahi les allées latérales: elles se tinrent debout pendant deux heures, apparemment sans fatigue ${ }^{16}$.» "Plusieurs centaines de gens, ne pouvant entrer à cause de l'affluence, durent se retirer, désappointées ${ }^{17}$. 》 Outre les plus notables citoyens de Toronto, on remarquait encore un grand nombre de ministres épiscopaliens, que la réunion annuelle de la Church Society assemblait précisément à cette époque de l'année: ils allaient mettre à profit, croyait-on, les avertissements du conférencier au sujet des tendances romanisantes à l'intérieur de leur Église, et de la protection à assurer au système scolaire national, que l'activité des catholiques, dirigés par Mgr de Charbonnel, était en train de disloquer.

Le président de la soirée, John Arnold, affirma d'abord que Gavazzi était bien connu en Europe pour s'être efforcé de promouvoir la cause de la liberté civile et religieuse. Depuis toutefois qu'il s'était réfugié en Angleterre, il paraissait avoir assumé un caractère plus nettement opposé au catholicisme. C'était «en dénonciateur impartial des erreurs de l'Église de Rome»qu'il venait à Toronto.

Gavazzi se leva ensuite et s'avança de quelques pas sur l'estrade au milieu des applaudissements de l'auditoire. Il était

13 Globe, May 21, 1853.

14 Gavazzi, Memorie, 091781.

15 Masters, op cit., 90.

16 Globe, June 2, 1853.

17 The North American, June 3, 1853. - Les détails qui suivent sont empruntés à ces deux derniers articles. 
revêtu de sa soutane noire de barnabite et d'un manteau, qui parurent très amples: deux croix tricolores, l'une sur la poitrine, l'autre sur l'épaule gauche, mettaient leur note vive sur ce deuil permanent.

Se drapant dans son manteau, l'orateur éprouva tout d'abord le besoin de s'excuser de son anglais approximatif, puis il expliqua pourquoi il portait encore son habit de clerc: "Ce fut autrefois, dit-il, mon costume monastique quand j'appartenais à l'ordre des barnabites, et ce fut aussi mon costume italien lorsque j'étais le premier aumônier dans notre croisade contre l'Autriche; mais ce vêtement n'est plus un habit religieux, et je le porterai jusqu'au moment où je pourrai retourner dans mon pays. Mes compatriotes doivent me revoir sous ce costume, si je veux qu'ils me reconnaissent: tel je fis ma croisade contre l'Autriche, tel je retournerai dans ma chère Italie pour reprendre cette croisade contre l'Autriche et la France - toutes les deux barbares jusqu'à ce qu'elles soient chassées de ma patrie. Ces croix que vous voyez sur mon habit ne sont pas des croix catholiques (Romish), ce sont des croix tricolores. C'était notre cocarde en Italie, quand nous fîmes notre croisade en 1848. Cette croix, que Pie IX bénit, m'est devenue chère, non comme croix catholique, mais parce qu'elle est notre cocarde italienne. Cette médaille (pointant de l'index la médaille sur sa poitrine) n'est pas une médaille catholique. Ce n'est pas une médaille jésuitique. C'est une médaille militaire. »

Après s'être ainsi décrit, Gavazzi fit sa profession de foi: «Je ne suis pas protestant: je suis chrétien », quoiqu'il révérât toutes les sectes. S'il adoptait quelque forme du protestantisme, cette adhésion contrarierait sa future mission en Italie: «Ma mission n'est pas de protester, elle est de détruire; ma mission est de détruire, d'anéantir dans ma chère Italie le pape et le papisme. Donc ne m'appelez pas protestant, car je n'en suis pas un, mais appelez-moi «destructeur »: c'est là mon nom. »

Après cette longue introduction, il aborda enfin son sujet proprement dit: Le système papal est l'aveuglement. Parce que les catholiques ne peuvent pas lire librement la Bible: "Ils n'ont pas la parole de Dieu et dès lors, généralement parlant, les catho- 
liques sont aveugles. » «L'Église catholique désire répandre l'ignorance et les ténèbres parmi le peuple, parce que plus le peuple est ignorant, plus son autorité est forte, mieux assise est sa domination. »

Gavazzi s'étendit sur l'influence grandissante du romanisme dans tous les pays, en Angleterre, aux États-Unis et au Canada, et exhorta ses auditeurs à s'y opposer de toutes leurs forces, s'ils ne voulaient pas devenir romanistes eux aussi: "Pas de paix, pas de paix, pas de paix avec Rome ! », s'écria-t-il, et une clameur de tempête répondit en écho à l'appel haineux de l'Italien.

«Protestants du Canada! rappelez-vous, vociférait-il au terme de sa diatribe, les paroles d'un pauvre exilé italien: "Gardez votre Bible! (vifs applaudissements). Gardez votre Bible dans vos écoles (acclamations), parce que c'est la nourriture appropriée à vos enfants. Gardez votre Bible, car sans la Bible vous n'êtes pas protestants. Gardez votre Bible, parce que des protestants sans Bible sont comme des flammes peintes sur une toile: elles n'ont pas de chaleur. Des protestants sans Bible sont des lions sans griffes; ils sont Samson sur les genoux de Dalila (applaudissements frénétiques). Gardez votre Bible! C'est l'origine de tout bonheur, de toute prospérité, de toute félicité. »

« Nous ne vîmes jamais auditoire, concluait le journaliste du Globe, plus complètement gagné par l'enthousiasme qu'à ce moment. Les applaudissements étaient assourdissants, et quand un Monsieur que nous ne reconnûmes pas, bondit sur un banc pour réclamer trois hourras en l'honneur du conférencier, on les donna d'un tel cœur que nous n'avions jamais vu les paisibles citoyens de Toronto s'animer à ce point. Nous aurions aimé que chaque politicien qui songe à une union avec le romanisme et à distribuer de l'argent protestant aux écoles catholiques, eût été là pour percevoir le sentiment du public. »

Sa seconde conférence, Gavazzi la donna dans Knox Church, l'un des trois temples du Free Church. "Ce grand édifice, apprenait le Globe à ses lecteurs, était rempli, le $1^{\text {er }}$ juin, pour l'entendre. Le conférencier, qui s'était remis des fatigues de son voyage, fut encore plus brillant et plus énergique que le soir précédent. Sa description des attaques insidieuses de Rome par l'intermé- 
diaire des Sœurs de Charité fut peut-être le morceau le mieux enlevé de son discours. Nous avons l'ennui d'ajouter qu'on ne put convaincre l'orateur de prolonger son séjour. Il se rend incessamment à Montréal et à Québec, où il obtiendra, nous n'en doutons pas, un immense succès ${ }^{18}$. 》

«Knox Church, écrivait de son côté un journaliste catholique, était l'arène qui convenait à Gavazzi. L'atmosphère elle-même était saturée de l'arôme des invectives antipapistes, et il était impossible de monter sur le trépied sans en éprouver l'inspiration exaltante ${ }^{19}$.

«La farce est terminée », concluait-il non sans sarcasme. Quant à Gavazzi, il conserva le meilleur des souvenirs de son passage dans la ville. Un an plus tard, de retour en Irlande, il disait à Belfast: "Mon espoir (pour le Canada) repose seulement sur Toronto, dans le Haut-Canada. Là le protestantisme est vigoureux, et j'espère que Toronto sera, dans un proche avenir, la métropole du Canada britannique pour répandre le protestantisme sur le reste du pays ${ }^{20}$.

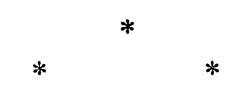

Malgré qu'il en eût, l'ex-barnabite ne pouvait s'attarder plus longtemps parmi ses admirateurs ontariens: son agenda lui enjoignait impérieusement de se mettre en route pour Québec. Il prit donc, le 2 juin ${ }^{21}$, l'un des bateaux qui faisaient la navette entre Toronto et l'île de Montréal, débarqua à Lachine, d'où le chemin de fer ${ }^{22}$ le mena dans la métropole. Des amis l'y rencontrèrent dans la journée du $3^{23}$. Un message fut alors expédié,

18 Globe, June 2, 1853.

19 The Mirror, June 3, 1853.

20 Banner of Ulster, May 13, 1854. - A l'occasion du séjour de Gavazzi à Toronto, on réédita Six Lectures delivered in the Round Room of the Rotunda, Dublin, by Father Gavazzi: with a Biographical Sketch of the Author (Toronto, Donogh and Brother, 1853), In-12, 175-240. (Pages précédées de The Trial of Antichrist, otherwise the Man of Sin, for High Treason against the Son of God, by W. L. S. G. (William Gregory)).

21 Gavazzi, Memorie, 091782.

22 The Monthly Railway \& Steam Navigation Guide for British North America (Montréal, 1853), 10.

23 An Eye Witness, The Gavazzi Riot and Outrage of 9th June, in Montreal (Montréal, 1853), 1. 
grâce au télégraphe électrique, dont une ligne avait été aménagée six ans plus tôt par The Montreal Telegraph Company entre Toronto et Québec ${ }^{24}$, à Benjamin Cole Jr. que Gavazzi était sur le point d'arriver par bateau dans la capitale et qu'il convenait d'aller l'accueillir au débarcadère ${ }^{25}$; en effet, le chemin de fer ne reliant pas encore les deux villes ${ }^{26}$, le bateau se révélait le véhicule tout indiqué pour le voyageur désireux d'utiliser les heures nocturnes, car le service quotidien, qui existait depuis 1826, avait été doublé, à partir de mai 1833 , d'un service de nuit ${ }^{27}$.

Le 4 juin au matin, tel que prévu, Gavazzi débarquait à Québec ${ }^{28}$. Accostait également en cette journée le Santipore, venant de Gibraltar ${ }^{29}$ et ayant à son bord une division du $26^{\text {e }}$ régiment, composée de Caméroniens, qui eussent certes été étonnés à l'extrême si on leur avait alors appris qu'ils ne tarderaient pas à s'acquérir au Canada une sanglante célébrité, par la présence de cet Italien dont les journaux de la ville signalaient l'arrivée, qui coïncidait avec la leur ${ }^{30}$.

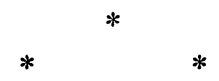

L'altier promontoire québécois n'avait pas fini de jeter dans une stupeur admirative l'étranger qui le contemplait pour la pre-

24 Mary Quayle Innis, An Economic History of Canada (Toronto, 1945), 150.

25 Témoignage de $\mathrm{B}$. Cole $\mathrm{Jr}$. au procès des agitateurs du temple de Chalmers (The Quebec Gazette, January 28, 1854).

26 Rappelons que le chemin de fer du Grand Tronc entre Montréal et Lévis ne fut inauguré qu'en 1854 (George Gale, Historic Tales of Old Quebec (Québec, 1923), 45); par ailleurs, le premier chemin de fer sur la rive Nord de Québec à Montréal ne fonctionna qu'en 1879 (Raoul Blanchard, L'Est du Canada français, 2 vol., (Montréal, 1935), II: 221).

27 Gale, op. cit., 135. - Durant les mois d'été, le paquebot, quittant Montréal à 6 ou $7 \mathrm{~h}$. du soir, abordait à Québec vers 4 ou 5h. du matin (The Guide to Montreal and its Environs, 52).

28 The Quebec Mercury, June 4, 1853.

29 Départ annoncé dans The Gibraltar Chronicle et reproduit par The Montreal Transcript, May $30,1853$.

${ }^{30} \mathrm{Le}$ lendemain, le deuxième transport du même convoi, le Thomas Arbuthnot, jetait l'ancre à son tour devant Québec. Au cours des manouvres d'accostage, le commis aux vivres se noya accidentellement (The Quebec Mercury, June 5, 1853) : sinistre augure pour les esprits superstitieux ! Mais en l'occurrence les événements allaient dépasser en horreur les pressentiments même les plus sombres. 
mière fois. Même un touriste ${ }^{31}$ chevronné comme le romancier irlandais Charles James Lever, qui avait déjà en 1849, au moment où il écrivait The Confessions of Con Cregan, promené une curiosité avide à travers maint paysage illustre de l'Europe, avouait sans réticence l'émerveillement dont il se sentait de nouveau envahir, en se remémorant l'instant où, du navire d'émigrants qui l'avait amené à Québec, s'était dressée devant ses yeux la masse du Cap Diamant hérissée d'ouvrages militaires: «As viewed from Diamond Harbor, a more striking city than Quebec is seldom seen. The great rock rising above the Lower Town, and crowned with its batteries, all bristling with guns, seemed to my eyes the very realization of impregnability. I looked from the ship that lay tranquilly on the water below (...) to the Highlander who paced his short pat as sentry, some hundred feet high upon the wall of the fortress $(\ldots)^{32}$.»

Quand le voyageur détacha enfin les yeux de l'éperon rocheux, auquel le mouvement de va-et-vient de la sentinelle conférait tout son relief de géologique immuabilité, ce fut pour les diriger, droit devant soi, vers un spectacle qui en était l'antithèse absolue par son extraordinaire animation: «There were people everywhere; all was motion, life, and activity », écrit encore Charles Lever ${ }^{33}$. En effet, Québec, à cette époque, construisait des navires et exportait du bois. Plus de cinquante chantiers maritimes retentissaient d'une activité fiévreuse le long du fleuve, à Sillery, à Lévis, à l'île d'Orléans, sur les vastes grèves de la rivière Saint-Charles. L'année 1853, précisément, devait être celle où l'on construisit le plus de bateaux à Québec, soit soixantedix-neuf, avec une moyenne de tonnage de sept cent vingt et une tonnes par unité ${ }^{34}$.

C'étaient surtout les Canadiens français qui, charpentiers, forgerons, voiliers, cordiers, constituaient la main-d'œuvre, alors

31 L'on sait que le mot venait d'entrer dans la langue: le Dictionnaire étymologique de la langue française d'Oscar Bloch indique l'année 1816; et Les Mémoires d'un touriste de Stendhal sont de 1838.

32 The Works of Charles Lever, (6 vol. in-8, New York, (s.d.) ) 4: The Confessions of Con Cregan, 401.

33 Id., ibid., 401.

34 Narcisse Rosa, La Construction des navires à Québec et ses environs (Québec, 1897), 24-25. 
que les Anglais possédaient la très grande majorité des chantiers; en revanche, les Irlandais avaient la prédominance - une prédominance incontestée - dans la manutention du bois, dont le commerce atteignit son apogée de 1840 à 1858, surtout lors de la guerre de Crimée: les représentants des firmes britanniques de bois avaient quitté la Baltique pour l'Amérique du Nord ${ }^{35}$.

Chaque année, des millions de pieds cubes de bois équarri parvenaient à Québec venant de l'Outaouais et de ses tributaires. Des Canadiens français et des Écossais, pour la plupart, en acheminaient les «cages » vers leur destination; des manœuvres irlandais, dont le nombre s'éleva jusqu'à six, même sept mille, s'attribuaient la tâche d'arrimer ce bois sur les navires ${ }^{36}$.

$\mathrm{Au}$ printemps, de bonne heure en mai, et à l'automne, les bateaux arrivaient de l'Europe pour transporter outre-Atlantique leur stock de bois. Le Saint-Laurent devant Québec offrait alors un spectacle unique en son genre aux amateurs de pittoresque et de couleur locale ${ }^{37}$ : on eût dit une forêt de mâts, tellement les navires étaient rapprochés les uns des autres; certains étaient accostés aux estacades flottantes, mais bien plus nombreux ceux qui, attendant leur tour, mouillaient dans le lit du courant.

Puis commençait le chargement du bois. Les entrepreneurs à la tête de leurs équipes d'ouvriers, dans un grand bruit de cris et de jurons où se percevaient toutes les variétés du brogue des trente-deux comtés, s'attaquaient à cette tâche, qui était à la fois pénible et dangereuse. On pouvait prendre d'une à trois semaines pour charger un navire, suivant son tonnage ${ }^{38}$.

Les Irlandais toléraient difficilement que d'autres qu'euxmêmes s'employassent à cette besogne. L'accès de certains quais était pratiquement interdit aux Canadiens français. L'intrus qui s'y aventurait était rossé consciencieusement! Paddy n'était

35 Edwin C. Guillet, Early Life in Upper Canada (Toronto, 1933), 243.

36 William Wood, The Storied Province of Quebec, (4 vol. in-4, Toronto, 1931), I : 173-174.

37 Comme Lever: «...vessels of every nation lie at anchor, some with the sails hung out to dry, gracefully drooping from the paper spars; others refitting again for sea, and loading the huge pine-trunks, moored as vast rafts to the stern. 》 (Op. cit., 401.)

38 George Gale, Quebec Twixt Old and New (Québec, 1915), 72-73. 
pas d'humeur à laisser Jean-Baptiste s'infiltrer dans son fief, qui s'étendait du Marché Champlain aux limites de la ville ${ }^{39}$.

Lancement de navires, arrimage du bois faisaient donc du port de Québec le théâtre d'une agitation fébrile. D'autres indices laissaient prévoir que cette activité deviendrait encore plus intense. Ainsi le premier vapeur à réaliser en vingt jours la traversée entre Liverpool et Québec fut le S.S. Genova, qui jetait l'ancre dans les eaux québécoises le 9 mai $1853^{40}$. Bref, c'était un mouvement, d'année en année plus accentué, de navires: bientôt plus de mille par an mouillèrent dans le port de Québec. Le chiffre annuel moyen des entrées, de 1851 à 1855 , fut de $1.211^{41}$. Un exemple fera mieux voir ce progrès sensible même de mois en mois: au $1^{\text {er }}$ juillet 1852,441 vaisseaux, totalisant 182.000 tonnes, avaient pénétré dans le port; à la même date, l'année suivante, 524 navires étaient arrivés, représentant un tonnage de 210.174 , soit 28.174 tonnes de plus que l'année précédente ${ }^{42}$.

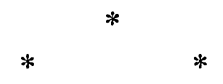

Gavazzi n'a pas confié au papier - du moins à notre connaissance - les sentiments que Québec suscita chez lui, lorsque, accompagné de quelques amis qui étaient allés à sa rencontre au débarcadère ${ }^{43}$, il gravit la Côte de la Montagne et, parvenu au sommet, à proximité de l'édifice parlementaire, franchit la porte Prescott, pour se rendre à son hôtel. Sans doute éprouva-t-il des impressions assez semblables à celles d'un autre voyageur qui visitait la ville trois semaines plus tard, le Sud-Américain Benjamin Vicuña Mackenna, qui écrivait le 27 juin 1853 dans son journal: "Aussitôt débarqués, franchissant des fossés et des poternes, nous arrivâmes par des rues tortueuses et escarpées à l'hôtel Russell, dans la ville haute. Québec me parut une cité féodale, sombre, embastillée, mais active et commerçante, tout le

39 John Francis Maguire, The Irish in America (New York, 1867), 92.

40 Gale, Historic Tales of Quebec, 44.

41 Blanchard, L'Est..., II : 206.

42 The Montreal Transcript, July 5, 1853.

43 Gavazzi, Memorie, 091784. 
contraire de Montréal. Cette dernière est avant tout la capitale française, tandis que Québec, siège du gouvernement, est plutôt ville anglaise ${ }^{44}$.

C'est précisément à l'hôtel Russell que Gavazzi descendit ${ }^{45}$. Cet hôtel, situé rue du Palais, du côté opposé à l'actuel hôtel Victoria, était alors très réputé ${ }^{46}$ et le plus vaste de la ville. C'est là que logeaient les personnages de distinction du Canada et de l'étranger qui s'arrêtaient dans la capitale. D'abord connu sous le nom d'hôtel Albion, il avait passé, une dizaine d'années après sa construction, entre les mains de Charles Hoffman, en 1834. En 1843 il était devenu la propriété des frères écossais Russell ${ }^{47}$, qui, en mai 1852, informaient le public qu'ils avaient restauré l'édifice, lequel pouvait désormais « recevoir commodément un nombre de voyageurs double de celui d'aucun hôtel de la ville»; le jouxtait une «nouvelle salle de concert (...) éclairée au gaz », munie d' "appareils ornés très coûteux » et suffisamment spacieuse pour $\ll$ contenir cinq cents personnes ${ }^{48}$.

Gavazzi logea donc, pendant son séjour à Québec, à l'hôtel Russell, à proximité de l'église des Irlandais, St. Patrick, édifiée depuis vingt ans. Le curé McMahon n'était plus là pour apaiser, grâce à un ascendant qui n'avait été rien de moins que jupitérien sur ses ouailles, l'émeute toute prochaine, puisqu'il était décédé le 3 octobre 1851 et avait été inhumé dans l'église qu'il avait érigée ${ }^{49}$.

Tout de suite les journaux annoncèrent le motif de la présence de Gavazzi dans la ville: donner des conférences contre le «papisme ». Le soir du même jour, 4 juin, comme le publièrent les feuilles anglaises, l'ex-barnabite devait prononcer une causerie intitulée: Le système papal est l'aveuglement ${ }^{50}$. Le récent succès de Toronto l'avait sans doute incité à exploiter à fond un thème

44 Obras completas de Benjamin Vicuña Mackenna publicadas por la Universidad de Chile, (16 vol. in-8, 1936-1940), I: Paginas de mi diario durante tres años de viaje 1853-1854-1855, 196.

45 Gavazzi, op. cit., 091784.

46 «... reputato il megliore », écrit Gavazzi, ibid., 091784.

47 Gale, Historic Tales ..., 214-215.

48 Pays, 7 mai 1852.

49 Gale, op. cit., 119.

50 The Quebec Mercury, June 4, 1853. 
qui déchaînait infailliblement des tempêtes d'applaudissements parmi ses auditeurs protestants.

On avait demandé, à cette fin, aux propriétaires de l'hôtel Russell l'usage de leur salle de concert, mais, avisés et craignant sans doute quelque tumulte, les prudents Écossais s'étaient dérobés ${ }^{51}$.

Une agitation populaire était à prévoir: nul besoin d'être prophète pour cela. Car les passions religieuses étaient plus exacerbées que jamais. Elles s'amalgamaient étroitement avec les querelles raciales. On a vu dans le chapitre précédent ${ }^{51 a}$ qu'en 1851 les Irlandais, à Québec, comptaient 9.000 têtes et les AngloÉcossais, 7.328; les Irlandais habitaient la rue Champlain et les rues avoisinantes, à proximité de leurs emplois, zone sordide dépassant en saleté, au témoignage de l'un de leurs compatriotes, le ghetto de Rome ${ }^{52}$ et coupe-gorge où les scènes de violence agrémentées de beuveries crapuleuses interdisaient au citoyen autre qu'irlandais de s'aventurer après la tombée de la nuit ${ }^{53}$.

Refoulés, surtout à partir de 1847, par l'affluence des fils d'Érin, les Anglo-Écossais avaient émigré vers la haute-ville. Toute une floraison de temples protestants marquaient mieux que tout autre indice les points où se groupaient de préférence les membres des diverses confessions. La cathédrale anglicane ${ }^{54}$ s'élevait presque sur le site de l'église des récollets, incendiée le 6 septembre $1796^{55}$. Les presbytériens avaient leur temple, St.

51 Correspondance envoyée au New York Daily Times, June 11, 1853, et datée de Québec, hôtel Russell, 7 juin 1853.

51a Cf. Robert Sylvain, Un «quarante-huitard》du Risorgimento au Canada: arrière-plans raciaux et confessionnels de l'équipée gavazzienne, dans la Revue de l'Université Laval, XI (mai 1957): 763.

52 Charles Lever, op. cit., 414.

53 «... not an inhabitant of the city, with money or character would have, for any consideration, put foot within this district after nightfall. The very cries that broke upon the stillness of the night were often heard in the Upper Town; and whenever a shriek of agony arose, or the heartrending cry for help, prudent citizen would close the window and say, «It is some of the Irish in the Lower Town, 》 - a comprehensive statement that needed no commentary 》. (C. Lever, ibid., 415.)

54 Construite en 1804 par l'Irlandais catholique Cannon (Nicholas Flood Davin, The Irishman in Canada (Toronto, 1877), 101). 191.

55 Ernest Gagnon, Le Fort et le Château Saint-Louis (Québec, 1908), 
Andrew's, depuis 1810 ; il se dressait à proximité du monastère des ursulines, sur un terrain donné deux ans auparavant par sir James Craig. Le pasteur en était le révérend John Cook, qui avait été ordonné à Cardross, Écosse, le 27 septembre 1835 et qui était arrivé à Québec le 30 avril $1836{ }^{56}$.

Le méthodisme wesleyen possédait son temple rue SaintStanislas. C'était un édifice tout récent. Il avait été précédé par un premier temple construit en 1816, par un deuxième érigé en 1831 rue Champlain; enfin, dans le quartier Saint-Louis, en 1839, par un troisième, qui devait disparaître lors d'un incendie ${ }^{57}$. La pierre angulaire du temple de la rue Saint-Stanislas, au voisinage de la prison, avait été posée le 31 mai 1848, et l'édifice inauguré le dimanche 7 octobre 1849 par le révérend Ritchie ${ }^{58}$ : bâti en pierre de taille, d'architecture gothique, il pouvait contenir 1.250 personnes ${ }^{59}$.

Enfin la « congrégation 》 du Free Church of Scotland disposait également d'un temple, Chalmers' Church, édifice surmonté d'un remarquable clocher de style gothique, construit rue SainteUrsule en 1852 et inauguré le 6 mars 1853. Le pasteur en était le révérend W. B. Clark, originaire de Maxwelltown, Dumfries, Écosse ${ }^{60}$.

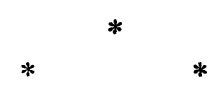

Quelques rues séparaient Chalmers' Church de St. Patrick, mais un antagonisme irréductible au double point de vue doctrinal et racial dressait une barrière quasi infranchissable entre presbytériens et catholiques, entre Écossais et Irlandais: des haines séculaires importées de leurs patries respectives n'avaient que trop d'occasions de se rallumer aux querelles politico-religieuses qui, précisément en ce printemps de 1853, mettaient aux prises

56 Gale, Historic Tales ..., 113.

57 Wood, The Storied Province .... I : 546.

58 Gale, op. cit., 115.

59 J. M. Lemoine, Quebec, Past and Present, (Québec, 1876), 407.

60 A. G. Doughty and N. E. Dionne, Quebec Under Two Flags. A Brief History of the City From its Foundation until the Present Time, (2 vol. in-8, Québec, 1903), II: 339. 
les parlementaires qui siégeaient alors dans la capitale du BasCanada. La session durait depuis le 19 août 1852, mais elle avait été interrompue du 10 novembre au 14 février par une épidémie de choléra ${ }^{61}$. Elle devait se prolonger jusqu'au 15 juin $1853^{62}$.

Elle se tenait dans l'édifice qui, section par section, de 1830 à 1852, avait remplacé l'évêché construit par Mgr de Saint-Vallier au haut de la Côte de la Montagne. Terminé, le nouveau palais législatif présentait une façade et deux ailes de deux étages sur rez-de-chaussée ${ }^{63}$.

Cette session fut tumultueuse: "réserves du clergé » et écoles séparées, autant de questions litigieuses qui divisaient les législateurs ${ }^{64}$. L'un d'eux, le récent député du comté de Kent, George Brown, luttait d'autant plus désespérément contre l'influence catholique et française dans la politique canadienne, qu'à Québec il constatait, plus qu'ailleurs, d'une façon tangible la puissance de l'Église catholique au Canada. De son siège de député, l'Écossais presbytérien, adepte du Free Church, le voluntarist selon le cœur du Dr. Chalmers, n'avait qu'à lever les yeux pour apercevoir dans les tribunes des auditeurs français et catholiques, parmi lesquels les taches sombres des soutanes cléricales ajoutaient une nuance supplémentaire de «papisme»! Brown crut donc devoir s'opposer à toute législation qui fortifierait cette Église et augmenterait ses privilèges ${ }^{65}$. C'est ainsi que, durant une seule session, il devint comme «la voix authentique, la voix la plus influente du Haut-Canada protestant ${ }^{66}$.

On se souvient que la veille, précisément, du jour où Gavazzi débarqua à Québec, Brown avait proposé dans l'assemblée légis-

${ }^{61}$ C'était la cinquième fois que le choléra asiatique visitait Québec (P.-G. Roy, Le Vieux Québec (première série, Québec, 1923), 257).

62 Thomas Chapais, Cours d'histoire du Canada, VII: 24. 101-102.

63 P.-G. Roy, Toutes petites choses du régime anglais, (première série), 888-890.

Cf. R. Sylvain, Un «quarante-huitard»..., RUL, XI (juin 1957) :

65 John Lewis, George Brown, Coll. The Makers of Canada, (Toronto, 1907), 123.

66 Donald Creighton, John A. Macdonald. The Young Politician (Toronto, 1952), 191. 
lative l'abolition des écoles séparées ${ }^{67}$. Le lendemain, il avait suggéré de renvoyer à six mois les bills qui donneraient la personnalité civile à la congrégation des hommes de Montréal et aux Irlandais catholiques de Québec; mais il n'avait pas eu de succès: quelques députés seulement avaient voté en faveur de cette mesure ${ }^{68}$.

Tous ces incidents s'ajoutaient à ceux qui, à partir de 1850 , excitaient les haines religieuses: "Depuis la création des évêchés catholiques en Angleterre, écrivait un journaliste québécois, la presse protestante du Canada n'a cessé de déverser l'injure et l'outrage sur le pape, le clergé catholique et le catholicisme; les calomnies les plus absurdes ont été répétées avec joie par cette presse $(\ldots)$. Depuis l'ouverture de la session, les catholiques ont entendu fréquemment un député insulter le catholicisme et ses institutions, représenter les catholiques comme des imbéciles, des ignorants, des mendiants, des hommes immoraux; la catholique Irlande a eu une large part dans les injures vomies par ce député ${ }^{69}$. 》 La parole fulminante de Gavazzi fit déflagrer en manifestations meurtrières des passions depuis longtemps portées à l'incandescence.

La provocation débuta par des affiches qui furent placardées, dans la journée du 4, aux coins des rues et même jusque sur les murs des églises catholiques ${ }^{70}$. On y invitait les Québécois à assister à la conférence de l'ex-barnabite.

«On craignait, écrivait le rédacteur du Canadien, que nos co-religionnaires irlandais, qui n'entendent pas risée sur l'article de la religion, n'allassent troubler la fête ${ }^{71}$. »

Aussi avait-on mis la police sur un pied d'alerte.

67 Cf. R. Sylvain, op. cit., RUL, XII (septembre 1957) : 25.

68 Journal de Québec, 7 juin 1853.

69 Ibid., 9 juin 1853.

70 Ibid., $i d$.

71 Canadien, 6 juin 1853. 
La police québécoise comprenait en 1853 la force publique proprement dite ou municipale, la police fluviale et la garde de la prison, auxquelles s'ajoutait la police secrète ${ }^{72}$.

Des agents municipaux faisaient régulièrement la police des rues de Québec depuis juin 1838: ils étaient alors sous l'autorité du gouvernement; dix ans plus tard ils tombaient sous la coupe de l'administration municipale ${ }^{73}$, qui se chargeait de leur entretien depuis $1841^{74}$.

Les agents étaient recrutés par le comité municipal de police. Ils étaient sous les ordres immédiats du constable en chef Robert Henry Russell, qui occupait ce poste, en 1853, depuis dix-sept ans ${ }^{75}$, et relevaient de l'inspecteur de police ${ }^{76}$, l'Irlandais catholique John Maguire.

Le nombre des agents municipaux était d'environ trentesept en hiver et cinquante-trois en été ${ }^{\tau}$. Ce décalage numérique s'expliquait par une surveillance plus exacte qui devait s'exercer l'été, car vu l'activité du port, beaucoup d'étrangers - tout particulièrement des matelots, les jack-tar, - débarquaient à Québec. Les rixes étaient fréquentes dans la basse-ville surtout, où de surplus offraient leurs tentations bachiques trop de cabarets, la plupart situés rue Champlain ${ }^{78}$.

Quant à la police fluviale, établie depuis 1838, elle se composait, en 1853 , de vingt-huit hommes, qui formaient l'équipage de quatre chaloupes ${ }^{79}$ : ils devaient assurer la police du port

72 Déposition de Robert Henry Russell, constable en chef, dans le Rapport des Commissaires nommés pour faire une enquête sur la conduite des autorités de police lors de l'émeute de l'église Chalmers, le 6 juin 1853, avec les minutes des procédés et des témoignages rendus devant la dite commission (Québec, 1854), 23.

73 Gale, Historic Tales ..., 14.

74 Déposition de R. H. Russell, Rapport, 21.

75 Id., ibid., 19.

76 Rapport des commissaives, 2.

77 Ibid., 2.

78 Un dépouillement attentif du Mackay's Quebec Directory, New Edition, Corrected in July and August, 1852, donne le nombre effarant de 95 cabarets, dont 37 (11 tenus par des Irlandaises, probablement des veuves) pour la seule rue Champlain ! Viennent ensuite d'autres rues avoisinantes: Cul-de-sac, 7; Saint-Paul, 6; Marché de la Basse-Ville, 6; Sault-au-matelot, 4 ; Saint-Pierre, 4.

${ }^{79}$ Déposition de R. H. Russell, Rapport, 30. 
pendant les mois de navigation active. Ils étaient sous l'autorité du constable en chef Russell, qui pouvait de la sorte requérir leur aide en vue de prêter main-forte aux agents municipaux, quand besoin en était ${ }^{80}$.

Enfin, sous les ordres du shérif de la ville, William Smith Sewell, des agents étaient préposés à la surveillance des prisonniers, qui de 1814 à 1867 occupèrent l'édifice connu aujourd'hui sous le nom de Morrin College, rue Saint-Stanislas ${ }^{81}$. Ces agents étaient au nombre de douze ${ }^{82}$.

L'ensemble de la force policière québécoise, en juin 1853, comprenait donc quatre-vingt-treize agents; si l'on tient compte de la police secrète, quatre agents ${ }^{83}$, on arrive presque à la centaine. C'était à peine suffisant, même au point de vue des seules exigences ordinaires de sécurité, pour une population qui, avec les faubourgs, comprenait 45.000 âmes; à plus forte raison étaitce tout à fait inefficace lors des tumultes ${ }^{84}$, qui se renouvelaient fréquemment surtout lorsque affluaient des étrangers indésirables ${ }^{85}$.

Peu considérable quant au nombre, la police québécoise n'était pas composée d'éléments qui eussent pu en augmenter l'efficacité. On la recrutait trop souvent dans les rangs infimes de la société, car «les personnes bien qualifiées et la meilleure classe de journaliers qui pourraient former le corps de police» ne voulaient pas y entrer. C'est ce que corroborait le greffier municipal, l'historien François-Xavier Garneau, quand il dé25.

80 Déposition d'Olivier Robitaille, membre du comité de police, Rapport,

81 Gale, Historic Tales..., 24. - Morrin College rappelle le souvenir de Joseph Morrin, Ecossais qui émigra au Canada en 1798, fut le premier président de la Société médicale de Québec, président du Collège des médecins et chirurgiens du Bas-Canada, médecin à l'Hôtel-Dieu de Québec, président de l'école de médecine qui, en 1854 , céda la place à l'école de médecine de l'Université Laval (Cf. Charles-Marie Boissonnault, Histoire de la faculté de médecine de Laval (Québec, 1953), 137-141).

82 Rapport, 3.

83 Déposition de R. H. Russell, Rapport, 21.

84 Rapport, 3.

85 « Je crois, témoignait John Cook au procès dont il est question, qu'il serait très à propos d'augmenter le corps de police, si l'on prend en considération le dérèglement d'une partie de notre population et le grand nombre d'étrangers qui visitent cette ville en été, matelots et autres. 》 (Rapport, 68). 
posait au procès des émeutiers du 6 juin: «Il n'y a que la classe paresseuse et la moins respectable de la société qui s'engage ${ }^{86}$. »

De plus, ce qui diminuait la force de ce corps, c'est que, en cas de tumulte ou d'émeute, il y avait, infailliblement, des agents qui étaient d'intelligence avec les fomentateurs de troubles. Tirés des classes sociales inférieures, ils ne pouvaient oublier leurs origines une fois revêtus du costume de policier. On le vit bien, par exemple, dans le quartier Saint-Pierre, les 6 et 7 février 1853, lors des élections municipales: Narcisse-Fortunat Belleau allait être remplacé à la mairie par Ulric Tessier. Des Irlandais de la rue Champlain firent un mauvais parti à Angus McDonald, l'un des syndics du temple de Chalmers: «Je me trouvais alors, témoignait McDonald au procès ci-dessus mentionné, dans une petite chambre où se prenaient les votes pour l'élection; j'étais derrière une espèce de comptoir, où les électeurs venaient voter. La chambre était remplie d'hommes de police. Je fus tiré de derrière le comptoir et traîné jusque dans la rue par une troupe d'Irlandais de la rue Champlain, malgré ma résistance et l'aide de quelques amis. Quand ils m'eurent dans la rue, ils me frappèrent à coups de bâton et de pied, me tirèrent par les cheveux, jusqu'au moment où mes amis me secoururent. Les hommes de police qui étaient dans la chambre n'intervinrent en aucune manière; il y en eut un pourtant qui essaya d'éloigner ces gens, et qui était venu derrière le comptoir ${ }^{87}$. 》

Quand surtout des Irlandais étaient en cause, les agents de police irlandais n'intervenaient pas, fermaient les yeux pour ne pas sortir de leur inertie, bien mieux, étaient parfois de connivence avec la voyoucratie, car ils appartenaient à la même association de «ribbonistes ${ }^{88}$. Dans ces circonstances, l'inspecteur de police et le constable en chef pouvaient donner des ordres, ils n'étaient pas obéis.

86 Rapport, 35. - Un journaliste anglais écrivait de son côté, quelques jours après l'émeute: "We know the police force of Quebec well; they belong to that very class of people to whom the rioters belong. $\gg$ (The Morning Chronicle, June 15, 1853).

87 Rapport, 83. 768.

88 Cf. R. Sylvain, Un «quarante-huitard»..., RUL, XI (mai 1957) : 
En outre, ces deux hommes qui, en juin 1853, étaient respectivement - on l'a vu - John Maguire et Robert Henry Russell, ne s'entendaient pas ${ }^{89}$ : il y avait inimitié entre eux ${ }^{90}$. Le constable en chef s'était souvent plaint à A. McDonald, comme celui-ci en témoignait, du «manque de support » de l'inspecteur de police et «d'avoir été insulté et maltraité par lui devant ses subordonnés ${ }^{91} \gg$.

Ajoutons encore que, recrutés par le comité de police, les agents dépendaient de lui : le constable en chef n'avait qu'un «commandement nominal» et «que nonobstant la réclamation de l'inspecteur et surintendant de police, la véritable influence et la conduite de la force étaient exercées par le comité de police. Les officiers immédiats de la force ne pouvaient ni punir ni récompenser pour bonne ou mauvaise conduite, et conséquemment ne possédaient aucun contrôle efficace sur les hommes. Si donc il y avait quelqu'un qui fut responsable de la conduite de la police, c'était le comité de police, qui seul commandait actuellement (sic) les hommes ${ }^{92} \gg$. La police québécoise était donc pourvue, au témoignage de l'un des membres du comité de police, de «trop de chefs »: «Je crois, ajoutait-il, que c'est le chef de police qui devrait entièrement (sic) choisir les hommes et en être responsable envers l'autorité supérieure ${ }^{93}$.»

Absence d'un chef unique, absence de cette cohésion qu'elle eût possédée si elle avait été réunie en un seul corps au lieu d'être sectionnée en police municipale, en police fluviale et en garde de la prison, absence enfin de règlements précis outre ceux de la loi ${ }^{94}$, que le conseil de ville n'avait pas encore édictés ${ }^{95}$, autant de causes qui s'ajoutaient à celles qui ont été énumérées plus haut, circonstances qui expliquaient que, en 1853, « la police du

89 Déposition de George Hall, l'un des membres du comité de police, Rapport, 33.

90 Rapport, 12

91 Déposition d'Angus McDonald, Rapport, 82.

92 Rapport, 12.

93 Déposition de George Hall, Rapport, 82.

942 Victoria, ch. 2: «Ordonnance pour établir un système de police efficace dans les cités de Québec et de Montréal. »

95 Déposition de John Maguire, inspecteur et surintendant de police, Rapport, 40. 
Bas-Canada faisait preuve, par exception, d'inefficacité, contrastant d'une manière très défavorable avec les admirables modèles que donnent les arrangements (sic) de police d'Angleterre et d'Irlande ${ }^{96}$ », de telle sorte que c'était «un corps indiscipliné, insubordonné et incapable, sous le système actuel, de devenir discipliné et obéissant, et qui, sympathisant avec les personnes déréglées et violentes, était aussi peu efficace qu'un égal nombre d'hommes qu'on aurait tiré de la populace à laquelle on opposait ce $\operatorname{corps}^{97}$ ».

Quoi qu'il en fût, il fallait l'utiliser au mieux dans les circonstances présentes: des rumeurs ne circulaient-elles pas en ville, dans la journée du samedi 4 juin, laissant prévoir une émeute possible?

Ces bruits parvinrent aux oreilles de William Smith Sewell, shérif du district de Québec, qui, vers deux heures de l'aprèsmidi, courut au bureau de police et pria un agent, William Falconbridge, d'en avertir l'inspecteur Maguire. Celui-ci dépêcha Falconbridge auprès du constable en chef Russell avec l'instruction de se rendre, le soir-même avec la force publique, au temple méthodiste pour y maintenir la paix ${ }^{98}$.

Cet ordre fut exécuté. La presque totalité des policiers se rangea dans la cour de la prison ${ }^{99}$, que la seule largeur d'une rue séparait du temple. Même la police fluviale avait été requise. On l'avait postée à la station numéro un, face à la prison, pour pouvoir prêter son concours à la première alerte ${ }^{100}$.

Quelques agents seulement se trouvaient à proximité du temple lorsque la conférence commença. Tout était si calme qu'un membre du comité de police, William Headly Anderson, fit observer à l'inspecteur Maguire, avec qui il s'était rendu rue Saint-Stanislas, qu'il ne croyait pas que la force fût nécessaire

96 Rapport, 15.

97 Ibid., 15.

98 Déposition de William Falconbridge, Rapport, 65.

99 Déposition de John Mainhood, de la police, ibid., 75.

100 Déposition d'André Lemelin, de la police, ibid., 79. 
en l'occurrence et qu'il était d'opinion de la renvoyer à ses quartiers. Mais Maguire lui avait rétorqué que, quoique alors tout fût paisible, il pourrait se produire du tumulte quand la foule se disperserait, une fois la conférence terminée ${ }^{101}$.

Cette conjecture était certes défendable. N'y avait-il pas de quatre à cinq cents personnes qui, catholiques comme protestants, assistaient à une causerie dont le thème, sans rien dire de la personnalité du conférencier, n'était rien de moins qu'un amas d'insultes et d'imputations gratuites à l'adresse des catholiques, bien propres par conséquent à attiser les passions religieuses?

George Brown, qui avait pu lire dans son propre journal, à la date du 2 juin, un compte rendu de la même conférence prononcée à Toronto, s'était bien promis d'entendre Gavazzi le soir du 4 juin, et, vers sept heures, avait proposé de renvoyer au lundi suivant la séance parlementaire alors en cours; mais les députés s'étaient fait un malin plaisir de repousser la motion d'ajournement ${ }^{102}$. En revanche, le procureur général Drummond se rendit au temple méthodiste pour constater de visu les réactions de l'auditoire: il n'y vit aucune manifestation tapageuse, mais en rapporta le sentiment - c'est du moins ce qu'il déclara dans la suite - qu'il n'y avait pas d'appréhension à craindre au sujet des discours de Gavazzi ${ }^{103}$.

L'ex-barbabite n'impressionna pas moins par sa taille, son habit, son action oratoire, ses auditeurs québécois que ceux de Toronto. Présenté à l'assemblée par le shérif Sewell, à la grande indignation du rédacteur du True Witness, qui pensait qu'un fonctionnaire public ne devait pas s'immiscer dans les querelles religieuses qu'opposaient un groupe confessionnel à un autre, ${ }^{104} \mathrm{Ga}-$ vazzi parla debout sur une estrade élevée de quelqus pieds au-dessus du parquet, ce qui lui permit de reprendre pour cette fois une habitude chère aux prédicateurs italiens: aller et venir tout en

101 Déposition d'Anderson, ibid., 60.

102 Journal de Québec, 7 juin 1853.

103 Discours de Drummond à la Chambre, le 7 juin, reproduit par le Morning Chronicle, June 10, 1853.

104 True Witness, February 3, 1854. 
discourant. Derrière lui avaient pris place sur la même estrade une douzaine de personnes, dont évidemment le shérif Sewell.

On connaît déjà le thème de l'orateur. La seule modification que l'Italien apporta à un discours maintes fois répété déjà en Grande-Bretagne et aux Etats-Unis, puis quelques jours auparavant à Toronto, fut d'insérer des remarques agressives sur un sujet de la plus brûlante actualité, les écoles séparées du Haut-Canada, ce qui lui valut un regain d'ovations, dont le shérif Sewell prit l'initiative ${ }^{105}$, geste qui révolta les auditeurs catholiques, l'un d'eux surtout, l'Irlandais John Hearn ${ }^{106}$, mais sans qu'explosât, cette fois-ci, l'hostilité qui deviendra bientôt irrépressible. Ce que l'on connaît moins, c'est la prononciation anglaise toute personnelle de Gavazzi, dont voici un échantillon où éclatent à la fois l'inaptitude congénitale de l'Italien à rendre correctement le th et sa prédilection à faire vibrer le $r$ : «Oh ! de prriests, my brredrren! Dey arre the devil, my dearr brroderrs ! Dey arre de devil, my beloved brredrren !... Dey arre murrderrerrs, my dearr brredrren ! - men of blood and slaughterrs, my dearr brredrren - and de Iesuits dey arre de soul of de devil ! 107 »

Gavazzi parla durant deux heures, de huit à dix heures du soir, à 《un auditoire nombreux et extasié ${ }^{108}$ », écrivait un journaliste protestant.

Pendant ce temps plusieurs individus s'attroupaient autour du temple ${ }^{109}$, mais le constable en chef Russell et l'inspecteur de police, qui se trouvaient sur les lieux, n'étaient aucunement enclins à tolérer de leur part la moindre manifestation. Un geste de John Maguire le révéla péremptoirement: «Un groupe de six ou sept personnes, au témoignage de Mathew Ryan, se tenait dans la rue vis-à-vis une croisée ouverte du temple; je vis M. Maguire rejoindre ce groupe. M. Maguire semblait craindre

105 True Witness, June 10, 1853.

106 Il assistait à la conférence du 4 juin: déposition de Hearn, Rapport, 91.

107 Cité par Armand Yon, L'Apostat Gavazzi au Canada (1853), dans le Canada français, XXVI (décembre 1938) : 333.

108 The Quebec Gazette, June 6, 1853.

109 Déposition du notaire Edward George Cannon, Rapport, 89. 
qu'il ne se grossît davantage; il alla à ceux qui le formaient et les engagea à s'éloigner; et ils se séparèrent et s'éloignèrent ${ }^{110}$. 》

Ainsi, la conférence terminée à dix heures, les auditeurs se dispersèrent paisiblement et Gavazzi put regagner sa chambre à l'hôtel Russell, à quelques pas du temple où il venait d'invectiver.

Cette diatribe sectaire ne tarda pas à agiter les esprits. Les annonces parues dans les journaux anglais, les placards affichés ici et là, les commentaires passionnés de ceux qui, catholiques comme protestants, avaient entendu vociférer l'ex-barnabite contre le catholicisme, mirent la ville en effervescence. Il en résulta une exaspération d'une intensité inédite jusque-là à Québec ${ }^{111}$. Les 5 et 6 juin il n'était question dans les conversations que d'une émeute possible. Le clan irlandais de la rue Champlain, surtout, se déchaîna quand il apprit qu'une seconde conférence aurait lieu le lundi suivant, à telles enseignes que le curé de la paroisse de St. Patrick, James Nelligan - mais il ne disposait malheureusement pas de l'autorité morale de son prédécesseur, Patrick McMahon - se crut obligé d'exhorter ses paroissiens, le dimanche 5 juin, à rester calmes ${ }^{112}$, en dépit des provocations dont ils étaient l'objet. Et le Canadien du lundi laissait entendre que la journée ne se terminerait probablement pas sans qu'il y eût du tumulte, tellement les esprits étaient survoltés.

C'est dans la crainte d'une agitation possible ${ }^{113}$, que les syndics du temple méthodiste refusèrent de recevoir de nouveau Gavazzi, à moins que ses amis ne garantissent le temple, pendant un mois, contre tous les dommages qui pourraient survenir ${ }^{114}$.

110 Déposition de Ryan, ibid., 93.

111 Rapport des commissaires, 12.

112 The Quebec Mercury, June 7, 1853. - C'est donc au mépris de la vérité que Gavazzi écrit: «Ma succedeva la domenica, e basta a quel prete irlandese per aizzare contra di me le ire brutali de'suoi selvaggi papaleschi. 》 (Memorie, 091784).

113 Déposition de l'apothicaire John Bowles, syndic du temple méthodiste, Rapport, 57.

114 Déposition de Bowles, ibid., 57. 
Jeffery Hale, le principal truchement de l'Italien, écarta une proposition aussi onéreuse ${ }^{115}$. Force fut donc à Hale et aux autres partisans de Gavazzi de jeter leur dévolu sur un second édifice. Il fut question du temple presbytérien St. Andrew's, du moins si l'on en croit John Hethrington ${ }^{116}$. Mais le ministre John Cook, qui connaissait Gavazzi pour l'avoir entendu au cours d'un voyage en Écosse ${ }^{117}$, se souciait sans doute fort peu d'introduire chez lui un énergumène de la taille du prédicant gyrovague. Finalement on convint d'un autre temple presbytérien, mais appartenant au Free Church of Scotland, le Chalmers' Church ${ }^{118}$, qui avait été inauguré trois mois auparavant.

En dépit des rumeurs qui circulaient en ville, il ne semble pas que les autorités municipales aient été informées de ce qui se tramait. Le maire, Ulric Tessier, ne savait rien de ces conférences, si ce n'est par l'article du Canadien, qu'il prit pour « un badinage »: aussi ne pouvait-il en aucune façon conjecturer qu'il y aurait une émeute; il ignorait même l'endroit précis où Gavazzi parlerait le lundi soir ${ }^{119}$.

L'inspecteur de police n'avait pas été davantage mis au courant ${ }^{120}$. Seul le constable en chef avait été averti par Jeffery Hale, vers quatre heures trente le lundi après-midi, des propos alarmistes qui défrayaient les conversations. Il avait donc intimé aux agents de la police l'ordre d'être au poste le soir même, rue Sainte-Ursule ${ }^{121}$.

La conférence au temple de Chalmers commença à huit heures ${ }^{122}$. Gavazzi était allé, dans la journée, prendre une con-

115 Déposition de Hale, ibid., 63.

116 Déposition de Hethrington, ibid., 52.

117 Déclaration du révérend John Cook au meeting protestant tenu à Québec le 10 juin (The Quebec Mercury, June 11, 1853).

118 Déposition de Walter Charles Henderson, membre de la «congrégation 》 méthodiste et secrétaire du comité des syndics, Rapport, 60 .

119 Déposition de Tessier, ibid., 48.

120 Déposition de William Falconbridge, ibid., 65.

121 Déposition de Hale, ibid., 63.

122 The Montreal Gazette, June 9, 1853. 
naissance sommaire des lieux ${ }^{123}$, ce en quoi il fut bien inspiré, comme on le verra.

Le thème de cette seconde causerie - encore l'un des sujets préférés de l'orateur - était L'Inquisition ancienne et moderne. Il avait été abondamment placardé dans les rues. Aussi la curiosité attira-t-elle à Chalmers' plus de mille auditeurs, au témoignage du shérif Sewell, qui s'y était rendu avec sa famille ${ }^{124}$.

A l'extérieur, la police, au nombre d'une cinquantaine d'agents, c'est-à-dire le corps proprement dit de la police municipale seulement, s'était disposée, à huit heures trente ${ }^{125}$, sur deux rangs parallèles, depuis le côté nord du temple - à environ vingt ou vingt-cinq pieds de la porte principale ${ }^{126}$ — jusqu'à la rue Saint-Louis. Les policiers occupaient le trottoir du côté de l'édifice ${ }^{127}$, le visage tourné vers la foule ${ }^{128}$ qui, de l'autre côté de la rue, augmentait de minute en minute. A en juger par les vêtements, c'était surtout des ouvriers, auxquels se mêlaient de jeunes garçons; et à les entendre parler, on constatait bien vite, à leur accent, qu'il s'agissait d'Irlandais ${ }^{129}$. L'attitude de l'ensemble n'était rien moins que rassurante ${ }^{130}$ : plusieurs mettaient ostensiblement des cailloux dans leurs poches ${ }^{131}$; d'autres avaient à la main des bâtons ferrés, les célèbres shillelaghs. Vers neuf heures, la foule qui s'agglomérait devant le temple de Chalmers

123 Lettre de Gavazzi à Secchi de Casali, Québec, 8 giugno 1853, parue dans L'Eco d'Italia, 11 giugno 1853.

124 Déposition de Sewell, Rapport, 42. - Par contre, sept à huit cents personnes pour Jeffery Hale, ibid., 62 .

125 Déposition de John Mainhood, de la police, ibid., 73. - Ainsi la police fluviale et la police secrète n'avaient pas été requises, ce qui montre bien que, à la différence de la première conférence, Russell ne s'attendait pas à une émeute.

126 Déposition de Roger Finn, marchand, Rapport, 47.

127 Déposition de John O'Malley, ibid., 53.

128 Déposition de James Laughlin Corchoran, ibid., 57.

129 Charles Lever, dans le roman précité, donne des exemples amusants du brogue aux chapitres XIII-XVII (The Confessions of Con Cregan, 401-423).

130 The Quebec Mercury, June 7, 1853.

131 Déposition de Narcisse-Fortunat Belleau, ancien maire de Québec et conseiller législatif depuis le 23 octobre 1852 (John Charles Dent, The Last Forty Years: Canada since the Union of 1841, (2 vol. in-8, Toronto, 1881) II : 266), Rapport, 97-98. 
pouvait bien comprendre de quatre à cinq cents personnes, autant que du moins le laissaient deviner les ténèbres commençantes ${ }^{132}$.

Entre-temps Gavazzi faisait à sa façon l'histoire de l'Inquisition. Debout dans la chaire, dont on avait pour la circonstance augmenté la surface ambulatoire ${ }^{133}$, à une quinzaine de pieds du sol, revêtu de sa soutane et de son manteau de barnabite, égayés l'un et l'autre d'une croix tricolore à la poitrine et à l'épaule gauche, il décrivait «avec une vraie pantomime italienne», remarquait un journaliste anglais ${ }^{134}$, dans une langue extrêmement pittoresque, suivant le shérif Sewell, le tourment de l'eau ${ }^{135}$. Ses auditeurs éprouvaient des sentiments bien contradictoires. La plupart applaudissaient éperdument l'orateur, rythmant même leur assentiment de coups de bâton sur le parquet ${ }^{136}$. Mais d'autres, des manœuvres évidemment, si l'on en jugeait par les vêtements minables qu'ils portaient ${ }^{137}$, qu'on avait vus se détacher de la foule, payer à la porte le prix d'entrée - deux shillings, six deniers - et se distribuer, armés de leurs bâtons, dans les bancs ${ }^{138}$, faisaient d'énergiques signes de dénégation et manifestaient une agitation qui trouvait son exutoire en d'incessantes allées et venues de l'intérieur à l'extérieur de l'édifice et vice versa ${ }^{139}$. L'un d'eux, qui avait gagné une tribune latérale ${ }^{140}$, attira particulièrement l'attention par la fébrilité de son allure et de ses va-et-vient ${ }^{141}$.

Gavazzi avait déjà discouru pendant une heure, puisqu'il était environ neuf heures - des témoins affirmèrent, en effet,

132 Déposition de William Eadon, quincaillier, Rapport, 61.

133 Gavazzi, Memorie, 091785.

134 Cité par A. Yon, loc. cit., 333.

135 Déposition de Sewell, The Quebec Gazette, January 20, 1854. Description pittoresque, en effet, de ce supplice si l'on en juge par la reproduction qu'en fit The Quebec Gazette, August 15, 1853.

136 Déposition de John Hearn, Rapport, 91.

137 A tel point que Gavazzi se demandait « come tanta et tale ciurma-

glia avesse potuto pagare per l'ingresso 》 (Memorie, 091786).

138 The Morning Chronicle, June 7, 1853.

139 Déposition de John Hethrington, Rapport, 51.

140 Déposition de Robert Currie Geggie, ibid., 45.

141 Déposition de John Cook, ibid., 67. 
qu'ils avaient en ce moment perçu le signal du canon -, quand un individu, portant une chemise quadrillée bleue, pénétra comme un bolide dans le temple, enfila vivement l'allée sud, puis tout à coup s'arrêtant pile, leva le poing en dardant des yeux étincelants d'indignation dans la direction du conférencier. On lui cria de s'asseoir ${ }^{142}$. Il s'exécuta en choisissant le premier banc de la rangée du milieu, à quelque vingt-cinq pieds de la chaire ${ }^{143}$, bien en face de l'orateur, qui ne tarda pas à trouver « répulsive » « la trogne cireuse » de l'arrivant à l'allure si peu banale ${ }^{144}$; ce banc était déjà occupé par l'honorable Malcolm Cameron ${ }^{145}$, l'un des chefs cleargrit. Le perturbateur était John Hearn, comme on l'apprit bientôt, que les tirades anticatholiques entendues au temple méthodiste, le samedi précédent, avaient exaspéré jusqu'à la fureur.

Gavazzi continuait à parler intarissablement de l'Inquisition. Il personnifiait alors un prêtre catholique affirmant: «L'Église n'a jamais persécuté ! - Non ? répond Gavazzi ; et les Vaudois ? et les Dragonnades ? et les Maures d'Espagne ? et les Indiens d'Amérique ?...» En 1848, assure-t-il, quand les patriotes entrèrent dans Rome, ils y trouvèrent un four où l'on faisait rôtir les enfants, et des oubliettes où la victime tombait par un jeu de bascule... Or l'Inquisition est rétablie par le pape. Elle s'étend partout, même dans le Bas-Canada.

«Oui, continue Gavazzi, mais nulle part elle ne sévit avec plus de rigueur qu'en Irlande, où elle spécule sur les passions religieuses. Le cardinal Wiseman l'a nié: c'est ou un ignorant ou un imposteur; en tout cas, ce n'est pas un wise man ${ }^{146}$.

«It's a lie!» s'écria l'ouvrier qui venait de s'asseoir, mais Gavazzi n'entendit probablement pas l'interruption, couverte qu'elle fut par les applaudissements de l'auditoire. "Turn him out ! Mettez-le à la porte ! » crièrent des gens à qui elle n'avait pas échappé ${ }^{147}$. Au même moment, suivant le témoignage de

142 Déposition de John Hethrington, ibid., 51.

143 Déposition de John Hearn, ibid., 91.

144 Memorie, 091786.

145 Déposition de Malcolm Cameron, Rapport, 85.

146 Cité par Yon, loc. cit., 334.

147 Déposition de Hearn, Rapport, 91. 
Malcolm Cameron, « une ou deux personnes descendirent de la galerie et sortirent du temple, puis y rentrèrent ${ }^{148}$ ».

L'orateur, après avoir prié ses auditeurs de ne pas s'émouvoir ${ }^{149}$, quitta brusquement l'Inquisition et Wiseman pour s'en prendre à la société des «ribbonistes»: Gavazzi avait peut-être deviné dans l'individu qui était la cause de ce tumulte subit l'un des adeptes de cette association: "En Irlande, affirma-t-il en reprenant une calomnie qu'il colportait depuis ses prédications itinérantes à travers le Royaume-Uni ${ }^{150}$, fonctionne une terrible association secrète, la Ribbon Society, dont plusieurs prêtres catholiques font partie.» «It's a lie! » s'exclama de nouveau Hearn. "Turn him out! Turn him out! " ${ }^{151}$ rétorqua la foule et des auditeurs, exaspérés, se jetèrent sur le trouble-fête. Il s'ensuivit une mêlée indescriptible ${ }^{152}$. Au même instant, selon un témoin qui se trouvait dans l'une des tribunes latérales, "j'entendis un coup de sifflet venant d'en bas, et un de ceux du parti que j'avais remarqué dans le temple, et qui était monté dans les galeries, mit sa tête hors d'une fenêtre, - qui était ouverte à cause de la chaleur intense, - et poussa un hurlement; aussitôt il y eut une volée de pierres lancées dans les fenêtres et un groupe d'hommes armés de bâtons se rua dans l'édifice ${ }^{153}$ \%.

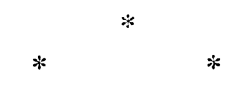

$\mathrm{Au}$ premier jet de pierres, presque tout l'auditoire s'était dressé, hurlant de frayeur ${ }^{154}$. Mais dominaient la stridence de ces cris les clameurs d'une trentaine d'ouvriers ${ }^{155}$ qui, armés de gourdins et de bâtons ferrés ${ }^{156}$, s'élançaient au pas de charge, par l'allée sud, dans la direction de la chaire, et vociféraient: "Pull

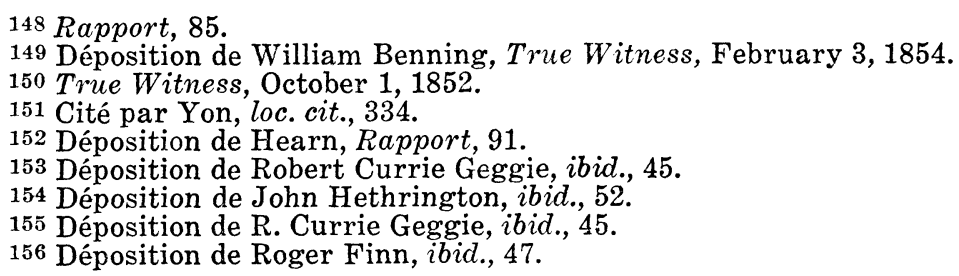


him out! Have his heart's blood! Sortez-le ! Saignez-lui le cœur ! ${ }^{157} \gg$

La bagarre était devenue générale entre Anglais et Irlandais. On s'acharnait sur Hearn: «Je crois qu'on m'eût ôté la vie, déclarait celui-ci par la suite, n'eût été l'intervention de quelques catholiques qui me connaissaient, aidés de la police et de la peur soudaine qui saisit mes assaillants en voyant quelques pierres passer à travers les carreaux ${ }^{158}$. 》 Les bâtons virevoltaient au bout de bras animés d'une frénésie meurtrière. Des gamins, qui étaient entrés à la suite des émeutiers, lançaient des cailloux ou se servaient de bibles et de livres de prières en guise de projectiles destinés surtout à l'orateur. Les personnes qui pouvaient fuir se précipitaient hors du temple. Le désordre était ponctué par le fracas des pierres qui pulvérisaient les vitraux, atteignaient les lampes à gaz et les boiseries pour choir, dans un tintamarre infernal, sur le parquet. Le révérend John Cook et le shérif Sewell essayèrent, mais en vain, de haranguer la multitude prise de panique. Une folle terreur s'était emparée des femmes. Les unes s'évanouissaient, les autres poussaient des cris perçants, de sorte qu'elles contribuaient à accentuer encore la confusion qui régnait à l'intérieur comme à ameuter la foule de l'extérieur. Dans les tribunes régnait une surexcitation extrême. Les cris d'effroi n'étaient interrompus que par des appels angoissés: «Où sont les troupes ? ${ }^{159}$

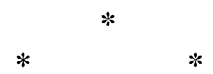

Cependant, la tourbe des émeutiers avait pris d'assaut la chaire dans laquelle Gavazzi était en quelque sorte prisonnier: les uns, par l'escalier qui y menait; les autres, parodiant, sans

157 «Il sangue del lui cuore 》. (Memorie, 091787).

158 Rapport, 92.

159 The Morning Chronicle, June 7, 1853. - Voici comment Ludovico Conti, le premier biographe et l'intime confident pendant de longues années de Gavazzi, décrit la scène: «... i vetri delle finestre e globi dei lumini cadevano con gran fracasso infranti, riempiendo quel luogo di culto di confusione e di grida selvaggie degli assalitori, e di spavento delle donne e dei fanciulli $\gg$. (In occasione del centenario della nascita di Alessandro Gavazzi: cenno biografico, Rome, 1909, 78). 
le savoir, les géants de la Fable, entassaient l'un par-dessus l'autre des pupitres de chantres ${ }^{160}$. Un jeune homme réussit même à saisir Gavazzi par le collet de son habit, mais l'Italien, qui était doué d'une force herculéenne, asséna à l'assaillant un coup de poing qui le précipita la tête la première du haut des marches ${ }^{161}$. Puis, se débarrassant en un tour de main de son manteau et se saisissant du siège lourd qui était derrière lui, le nouveau Frère Jean des Entommeures fit résolument face à ses adversaires ${ }^{162}$. Les coups pleuvaient dru à droite et à gauche sur le crâne des assiégeants, si bien que la chaise, qui servait à Gavazzi d'arme défensive, ne tarda pas à être mise en pièces ${ }^{163}$.

Un sergent d'artillerie, W. G. Lawson, qui se trouvait là, grimpa lestement au sommet de l'escalier et s'efforça d'écarter, non sans recevoir maints horions, les plus implacables des émeutiers; le secrétaire de Gavazzi, Paoli, suivit Lawson, et après s'être emparé du bâton de l'un des Irlandais, utilisait au mieux la trique dont le hasard l'avait pourvu ${ }^{164}$.

Que faisait donc la police pendant que l'ex-barnabite cherchait à repousser les assaillants ou du moins à vendre chèrement sa vie ? C'est ce que se demandaient bien des gens dans le temple. Jeffery Hale, le ministre Cook, d'autres encore, au comble de la surexcitation et de la colère ${ }^{165}$, sortirent par la porte principale: "Allez-vous nous laisser tuer ?» s'écria l'un d'eux, Robert Symes ${ }^{166}$.

Mais les agents avaient fort à faire pour contenir l'attroupement: une cinquantaine d'hommes en face de six cents person-

160 Déposition de Sewell, Rapport, 42; Memorie, 091788.

161 «... mordere il duro pavimento della chiesa con tale un tonfo, che anche l'orecchio mi rintrona 》! (Memorie, 091788). giugno.

162 Lettre précitée de Gavazzi à Secchi de Casali, L'Eco d'Italia, 11

163 Memorie, 091788-091789.

164 Ibid., 091786-091787.

165 Déposition de John Mainhood, Rapport, 73.

166 The Morning Chronicle, June 10, 1853. 
nes hurlantes et qui lançaient des pierres ! De plus il y avait collusion, comme on l'a vu, entre certains policiers et les agitateurs, parce qu'ils appartenaient, les uns et les autres, à la même société des « ribbonistes ».

A un moment donné un groupe d'individus à figures patibulaires ${ }^{167}$ se détacha de la populace, franchit la clôture qui séparait le temple de la rue et se jeta dans l'édifice ${ }^{168}$ en rugissant: 《Descendez-le !» Des policiers, obéissant à l'ordre du constable en chef, qui leur criait: «Tenez-les dehors $!{ }^{169}$, essayèrent de s'interposer " avec leurs mains et leurs bâtons » ${ }^{170}$, mais ils furent débordés et certains d'entre eux se virent entraîner, vellent nollent, à l'intérieur par la poussée irrésistible des assiégeants ${ }^{171}$; d'autres y entrèrent de leur plein gré, dix-huit à vingt, selon un témoin ${ }^{172}$, à telles enseignes que les agents demeurés à l'extérieur, réduits en nombre, furent d'autant plus impuissants à empêcher la foule de franchir le seuil du temple que, devenus la cible de volées de pierres, ils ne purent se maintenir à la porte, mais durent dégringoler les marches du perron ${ }^{173}$.

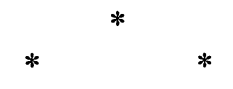

Les policiers de l'intérieur, jusque-là inertes sous prétexte qu'ils n'avaient pas reçu d'ordres précis ${ }^{174}$, mais probablement par sympathie inavouée pour les perturbateurs, ne se résolurent à agir vraiment que sur les injonctions de l'inspecteur de police, John Maguire, qu'on avait fini par repérer, alors qu'il ne se doutait pas du tout ${ }^{175}$ qu'une émeute faisait rage à Chalmers': entre sept et huit heures il causait avec des amis tout en faisant

167 «...uomini di sinistro aspetto». (Memorie, 091785).

168 Déposition de J. Mainhood, Rapport, 73.

169 Déposition de William O'Neil, de la police, ibid., 80.

170 Déposition de James Laughlin Corchoran, journaliste, ibid., 58.

171 Déposition d'André Lemelin, de la police, ibid., 79.

172 Déposition de John O'Malley, ibid., 53.

173 Déposition de William O'Neil, ibid., 80.

174 Déposition de Benjamin Cole, ibid., 72.

${ }_{175} \mathrm{Au}$ notaire Edward George Cannon, qui lui apprenait qu'on avait refusé l'usage du temple méthodiste à Gavazzi pour sa seconde conférence, Maguire avait répondu: «Je suppose qu'on n'entendra plus parler de ces lectures (sic). »(Déposition de Cannon, ibid, 89). 
les cent pas sur la terrasse Durham ${ }^{176}$. Après quoi il était revenu bien paisiblement à son domicile, 61 rue Saint-Louis ${ }^{177}$, où il arriva une dizaine de minutes avant le coup de neuf heures en compagnie de l'avocat John Young ${ }^{178}$. C'est là que William Edmund Duggan, dépêché par le constable en chef Russell, alla le quérir. En se rendant rue Sainte-Ursule, il croisa des gens qui revenaient du temple en courant: la situation était donc grave ! «Hommes, il faut que vous fassiez votre devoir !», s'écria-t-il en apercevant les premiers agents ${ }^{179}$. "Hommes, faites votre devoir ! », répéta-t-il à ceux de l'intérieur, au moment où des cailloux continuaient à pleuvoir par les fenêtres béantes ${ }^{180}$.

Le constable en chef, avec deux ou trois de ses subordonnés, s'était déjà rendu près de la chaire ${ }^{181}$. Là, depuis un quart d'heu$\mathrm{re}^{182}$, la mêlée était intense et confuse. Les poings et les bâtons s'abattaient à coups sourds sur les visages et les poitrines. Gavazzi, dans sa chaire, donnait libre cours à sa pugnacité de Bolonais. La chaise s'étant brisée dans ses mains, il happe un tabouret que lui lance un ami ${ }^{183}$. Las! son garde du corps improvisé, le sergent Lawson, perd l'équilibre et s'abat sur Paoli qui, quelques degrés plus bas, imprime de vigoureux moulinets à son bâton; les émeutiers, qui le pressent, font un suprême effort pour précipiter les deux hommes du haut de l'escalier. «Gavazzi, aidemoi !», s'écrie Paoli. Son compatriote se penche hors de la chaire dans sa direction, sans se rendre compte que deux autres agitateurs, mettant à profit ce moment d'inattention, se glissent derrière lui: ils ont tôt fait de le saisir par les jambes et de le faire culbuter par-dessus le rebord de la chaire, haute, comme on

176 Ayant fait raser les ruines du château Saint-Louis, incendié le 23 janvier 1834, Durham fit construire, en 1838, une terrasse, successivement agrandie en 1854 puis, cette fois-ci sur les conseils de lord Dufferin, en 1879 . (Ernest Gagnon, Le Fort et le Château Saint-Louis, (Québec, 1908), 211-212).

${ }_{177}$ Mackay's Quebec Directory. New Edition Corrected in July and August, 1852, 117.

178 Déposition de Young, Rapport, 88.

179 Déposition de W. E. Duggan, ibid., 95.

180 Déposition de John Wilson, ibid., 103-104.

181 Déposition de Malcolm Cameron, ibid., 85.

182 Rapport des commissaires, 10.

183 Memorie, 091789. 
l'a vu, de quinze pieds! Heureusement la tourbe qui grouille sous lui amortit sa chute ${ }^{184}$ et, jouant des coudes et des poings, il parvient à se dégager, non sans avoir reçu des coups de pied au visage, et à prendre l'escalier qui, tout à côté de la chaire, mène au soubassement. Connaissant l'endroit pour en avoir exploré les êtres dans la matinée et avoir emprunté ce chemin en pénétrant dans le temple environ une heure plus tôt, il se fraie, à travers les bancs, dans l'obscurité totale, un passage jusqu'à une chambre où il se barricade, échappant de justesse à ses poursuivants, qui le serrent de près ${ }^{185}$. Paoli a moins de chance que son patron; pris pour Gavazzi, il est sauvagement battu. Le reclus peut, de sa cachette, entendre un Irlandais demander rageusement à un autre: «Es-tu certain que c'est lui ? - Oui, lui répond-on. - En ce cas, tue la canaille: kill the bugger! $\gg^{186}$

Des policiers puis le médecin James Douglas descendent à leur tour. « J'entendis, témoignait plus tard le docteur Douglas au procès des émeutiers, qu'on battait quelqu'un qui était couché la face contre terre. Je pouvais distinguer la différence des coups portés à la tête de ceux qui étaient portés sur le corps ${ }^{187}$. 》

Douglas fit de la lumière en se procurant une bougie, ce qui mit les séditieux en fuite. Tout en examinant les blessures de Paoli, il aperçut se tenant à côté de soi l'inspecteur Maguire, qui s'enquit auprès des personnes présentes si elles savaient où se trouvait Gavazzi. Elles répondirent qu'il était là, en indiquant une chambre à la porte de laquelle elles veillaient ${ }^{188}$. Jugeant que le conférencier était désormais en sûreté, il remonta à l'étage supérieur, enjoignit à la police de faire évacuer le temple, mais

184 Gavazzi écrit qu'il tomba «mollemente sulla materassa elastica » des têtes et des épaules ! (Ibid., 091790).

185 Gavazzi, ibid., 091789-091790.

186 Déposition d'Angus McDonald, Rapport, 81.

187 Rapport, 104. - Sur Douglas, médecin à l'hôpital de la Marine et des Emigrés, Cf. Boissonnault, op. cit., 98.

188 Déposition de W. E. Duggan, Rapport, 95. 
la foule de l'extérieur continuait à faire le siège de la porte principale, qui ployait dangereusement sous une poussée ininterrompue. Maguire résolut alors de mander les troupes. Accompagné du capitaine Benson, du $66^{\mathrm{e}}$ régiment, qui avait assisté à la conférence, et d'Edward John Charlton, il quitta le temple par une porte latérale du soubassement, afin d'aller avertir le lieutenant-colonel John Henneigh Grubbe, commandant de la garnison. Les ténèbres étaient devenues opaques. Les trois hommes durent d'abord enjamber une haute clôture; après l'avoir franchie, ils se dirigèrent vers la rue Sainte-Ursule, mais à l'intersection de celle-ci et de la rue du côteau Sainte-Geneviève, Maguire fit une chute malencontreuse dans un fossé profond: il se releva péniblement en se plaignant de violentes douleurs aux reins.

Appuyé au bras de Charlton, l'inspecteur de police se rendit en clopinant au quartier des officiers du $66^{\mathrm{e}}$, puis au cercle militaire ${ }^{189}$, mais, la fatalité s'acharnant, Grubbe n'était pas encore rentré ! Il fallait donc pousser jusqu'à l'ancien collège des jésuites, converti en caserne depuis 1776. Parvenu à la rue des Jardins, Maguire rencontra la troupe qui montait. Puis, décidément très mal en point, il regagna son foyer et fit venir un médecin ${ }^{190}$.

C'était William Headley Anderson, membre du comité de police, qui avait alerté le militaire. Une centaine d'hommes du $66^{\mathrm{e}}$ régiment se dirigèrent donc vers le lieu de l'échauffourée. Mais il était déjà trop tard - neuf heures trente - car ils rencontrèrent, à l'intersection des rues Saint-Louis et du Parloir, les agitateurs qui s'étaient mis en marche, tout en poussant des hourras ${ }^{191}$, dans la direction de la basse-ville. Les Irlandais, plus d'une centaine dont beaucoup de gamins ${ }^{192}$, toujours donnant de

189 Respectivement au 15 et au 24 de la rue Saint-Louis (Mackay's Quebec Directory... 1852, 132).

190 Déposition de Charlton, Rapport, 93-94.

191 Déposition de William O'Neil, ibid., 80.

192 Déposition de William Eadon, $i b i d ., 62$. - Le procureur général les rencontra: d'après lui ils étaient de 100 à 150 dont plusieurs jeunes garçons (Morning Chronicle, June 10, 1853). - Pour Alexander Learmouth, ils étaient de 100 à 200 . Un autre témoin va jusqu'à 400 ! 
la voix ${ }^{193}$, se répartirent à la vue de la troupe en deux files, qui se rangèrent le long des bordures de la chaussée pour laisser le passage libre ${ }^{194}$ aux soldats en tenue rouge et buffleteries blanches de Sa Majesté la Reine Victoria. Mais l'un des ouvriers ne put s'empêcher de crier à l'adresse des militaires, qui survenaient bien tard pour mettre fin à une émeute déjà terminée: «Revenez chez vous, mes garçons ! " ${ }^{195}$ Le détachement s'engagea bientôt dans la rue Sainte-Ursule, où il se divisa en deux corps, dont l'un se rangea vis-à-vis du temple et l'autre alla se poster de piquet dans la cour du remiseur F. Driscoll, $431 / 2$ rue Saint-Louis ${ }^{196}$.

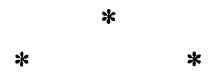

L'agitation était bien terminée. Les agents de police, qui étaient sortis du temple après en avoir expulsé les derniers perturbateurs, avaient reçu du constable en chef la consigne de libérer la rue: ordre bien inutile, puisque les auteurs du tumulte étaient déjà en marche vers leurs foyers ${ }^{197}$.

Le lieutenant-colonel Grubbe pénétra alors dans le temple. Il y trouva le maire, Ulric Tessier, qui approuva la décision prise ${ }^{198}$.

Tessier venait tout juste d'arriver, lui aussi, à Chalmers', car il n'avait été mis au courant de la bagarre qu'entre neuf heures trente et dix heures, alors qu'il assistait à une séance à l'assemblée législative (en plus d'être maire de Québec, il représentait le comté de Portneuf à la Chambre). Ayant hélé un cocher, il se fit conduire en toute hâte au temple méthodiste, où il croyait que cette seconde conférence de Gavazzi avait eu lieu, comme la première. Tiré de son erreur par une personne qui se trouvait là, il se rendit rue Sainte-Ursule. Dans Chalmers', il remarqua les dégâts aux fenêtres, aux lampes, aux boiseries;

193 Déposition de William Falconbridge, Rapport, 66.

194 Déposition d'Anderson, ibid., 59.

195 Déposition d'A. Learmouth, ibid., 71. 1852,60 .

196 Déposition de W. H. Anderson, ibid., 59; Mackay's Directory...

197 Déposition de J. Mainhood, ibid., 74.

198 Déposition d'Anderson, ibid., 59. 
des livres s'amoncelaient dans les allées et sous la chaire. Il y avait là tout au plus de trente à quarante personnes, qui parlaient avec animation, mais tout tumulte avait cessé. Il descendit dans le soubassement pour y trouver une douzaine de gens. Gavazzi avait quitté sa cachette. Le Dr Douglas s'affairait auprès de Paoli, sans connaissance, dont il pansait les blessures et qu'il essayait de faire revenir à lui. Le maire promit à Gavazzi de le reconduire ainsi que son secrétaire sous bonne garde à l'hôtel où il logeait. La troupe étant arrivée et Paoli ayant repris ses sens, Tessier fit monter l'ex-barnabite avec lui dans la calèche découverte qui l'avait amené, et Paoli prit place dans la voiture du Dr Douglas ${ }^{199}$ : on s'achemina alors, protégé par la troupe qui patrouillait les rues ${ }^{200}$, à l'hôtel Russell.

Le maire se rendit ensuite chez l'inspecteur de police ${ }^{201}$, qu'il trouva allongé sur un sofa, la figure exsangue, le pouls faible au témoignage du Dr Alexander Rowand ${ }^{202}$, souffrant, ainsi que l'affirmait un autre médecin appelé également en consultation, le Dr James Frémont, de contusions à l'épine dorsale et d'entorses aux muscles et aux ligaments du dos ${ }^{203}$.

Pendant que la calèche découverte, dans laquelle le maire de Québec et Gavazzi avaient pris place, se dirigeait vers la rue du Palais, la théorie vociférante des émeutiers, parvenue à l'endroit où la rue Buade débouche, grâce à une courbe de raccordement, dans la Côte de la Montagne, dévia vers la gauche pour se ruer dans la cour d'honneur de l'édifice parlementaire: la salle d'assemblée était encore éclairée en raison d'une séance tardive. N'ayant pu capturer Gavazzi, ils se mirent à réclamer à grands cris un autre de leurs ennemis acharnés: George Brown !

199 Déposition de Tessier, ibid., 48-49.

200 Lettre, déjà citée, de Gavazzi. - On avait décliné l'offre du maire de se servir de la police: après ce qui venait de se passer, on n'avait plus confiance en elle (Déposition de John Cook, Rapport, 68).

201 Déposition de Tessier, ibid., 49.

202 Déposition de Rowand, $i b i d ., 84$.

203 Déposition de Frémont, ibid., 99. 
Celui-ci se garda bien, comme l'on devine, de répondre aux tumultueuses invitations des Irlandais massés sous les fenêtres de la Chambre. Enfin un député finit par les convaincre de se retirer ${ }^{204}$. Ils franchirent alors la Porte Prescott, s'engagèrent dans la rampe fortement déclive pour retrouver leurs logis dans les rues Champlain, Cul-de-sac, Sous-le-fort, Sault-au-matelot, SaintPierre et Saint-Paul.

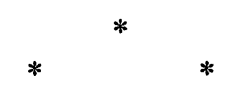

«La ville est toute en émoi », constatait le lendemain le correspondant d'un journal montréalais ${ }^{205}$. L'indignation, chez les protestants, explosait en articles de journaux et en meetings passionnés. "C'est avec le plus grand regret et en proie à une extrême humiliation, écrivait un journaliste québécois, que nous le disons: vivant sous un gouvernement protestant et alors que nous croyions être sous la sauvegarde d'un drapeau protestant, il est désormais avéré que les protestants de Québec ne peuvent s'assembler dans leurs propres sanctuaires, pour un but tout à fait légitime, qu'en autant qu'il plaît à ceux qui professent un credo religieux différent ${ }^{206}$.

«La ville de Québec, reprenait en écho un autre journaliste, celui-ci montréalais, s'est déshonorée irrémédiablement, étant la première ville sous le drapeau tolérant de l'Angleterre à pousser le cri de guerre de religion dans ce pays ${ }^{207}$. »

Mais, comme il fallait s'y attendre, c'est le journal de George Brown, The Globe, qui se déchaîna le plus violemment: «Le télégraphe nous informe que Gavazzi a été reçu à Québec avec toute la brutalité dont Rome se sert toujours quand elle peut l'employer en toute sécurité. » Un étranger qui a bravement combattu pour son pays, un homme éloquent est assailli à Québec: «Et cette scène se passe sous les yeux du gouvernement, au bas des murs de la citadelle de Québec, agrémentée, à la fin, d'un assaut sur

204 Alex. Mackenzie, The Life and Speeches of Hon. George Brown, (Toronto, 1882), 34.

205 Pays, 9 juin 1853.

206 The Quebec Gazette, June 9, 1853.

207 The Montreal Gazette, June 9, 1853. 
l'immeuble de la chambre d'assemblée elle-même. Quelle disgrâce pour Québec et pour toute la Province !» Le journaliste voulait croire que cette agression contre un temple protestant n'avait pas eu lieu «sans l'approbation de personnes influentes » dans le gouvernement, qui était « romaniste de cœur » et «trembl (ait) devant le clergé »: «Dans le Haut-Canada, les prêtres sont doux, paisibles et n'exigent que leurs droits; à Québec, où ils sont la majorité, ils sont des loups dévorants; ils empêchent toute discussion, abattant par la violence tous ceux qui leur font de l'opposition. »

Le journaliste en appelait donc à ses lecteurs: «Leur donnerons-nous maintenant de l'argent pour payer leurs instituteurs, pour bâtir des hôpitaux, des églises ? Leur permettra-t-on de nous faire la loi en politique ? (...) Jusqu'à quand les orangistes du Haut-Canada enverront-ils au parlement des hommes qui consentent à perpétuer les institutions catholiques romaines au Canada?»

En terminant, il lançait un cri d'alarme, où l'on pouvait pressentir l'effroi que lui causait la présence à Québec des évêques de Toronto, de Kingston et de Bytown, dont l'influence sur les législateurs ne serait pas négligeable lors du vote, le 14 juin, de An Act Supplementary to the Common School Act for Upper Canada ${ }^{208}$ : "Protestants, unissez-vous ou le catholicisme régnera, les prêtres l'emporteront dans l'enceinte législative ${ }^{209}$. »

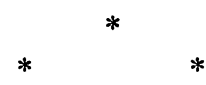

De bruyants meetings, à Québec, avaient déjà arrêté les résolutions à prendre pour réclamer auprès des autorités constituées des garanties concrètes contre le retour de semblables actes de violence. Les loges orangistes se multipliaient ${ }^{210}$ en vue de s'opposer aux loges de «ribbonistes »: c'était pour les

208 Cf. R. Sylvain, Un «quarante-huitard»..., RUL, XII (septembre 1957) : 25

209 Globe, June 9, 1853.

210 Correspondance datée de Québec, 8 juin 1853, et adressée au New York Express, June 11, 1853. 
protestants « un moyen prompt et commode » de s'unir pour se défendre, comme en témoignait l'avocat John Henry William, attaché à la rédaction du Quebec Mercury, au sujet d'une autre affaire dans laquelle s'étaient défiés Anglais et Irlandais, celle d'un meurtre perpétré à Saint-Sylvestre de Lotbinière ${ }^{211}$. Un comité se formait sous la présidence du ministre John Cook, afin de réclamer la punition des coupables et d'obtenir du gouvernement des mesures propres à assurer la protection des protestants dans l'exercice de leurs droits religieux ${ }^{212}$. L'un des premiers actes du comité fut de présenter une requête, signée de sept cents noms, au gouverneur général, lord Elgin, qui dans sa réponse se borna, diplomatiquement, à des souhaits évasifs et à laisser entendre que, s'ils avaient contemplé les derniers événements, Jacques Cartier et Champlain se fussent sans doute demandé si le pays avait gagné au change depuis l'époque des Hurons et des Iroquois! ${ }^{213}$

Le procureur général pour l'Est, l'Irlandais catholique Lewis T. Drummond, dès le 8 juin, fit part à la Chambre des mesures qui avaient été prises pour prévenir le retour de pareils incidents et arrêter les coupables. Il aborda alors un grief fréquemment soulevé par la presse anglaise: n'avait-on pas permis au converti américain Orestes Brownson, en avril 1850, d'attaquer ses anciens coreligionnaires précisément dans cette salle - la propriété commune des protestants et des catholiques qui, les années où le parlement siégeait à Toronto, servait pour les Québécois de salle de conférences ? Les protestants avaientils perturbé ses causeries ici et à Montréal, où le célèbre Yankee

211 Rapport des commissaires enquêteurs dans l'affaire du meurtre de Corrigan (Toronto, 1857), 36: «Je pense que les causes de l'extension de l'orangisme ne résultent pas du développement de ses principes politiques ou religieux, ni de l'admiration dont il est de plus en plus l'objet parmi la population protestante, mais simplement de l'idée que c'est un moyen prompt et commode de s'unir pour la défense. » - Et John Hume, juge de paix à Leeds, donnait un exemple concret lors du même procès: «J'ai appris l'existence des loges de ribbonistes dans Saint-Sylvestre avant le meurtre de Corrigan, et, depuis cet événement, il a été établi une loge d'orangistes dans Saint-Sylvestre. 》 (Ibid., 23) .

212 Discours de John Cook au meeting du 10 juin à l'hôtel-de-ville (The Quebec Mercury, June 11,1853).

213 The Quebec Mercury, June 11, 1853. 
était retourné à trois reprises ${ }^{214}$ ? Drummond dut admettre que les Anglais s'étaient révélés plus tolérants que les Irlandais, mais il omit de souligner la différence énorme qui existait entre un conférencier de la stature intellectuelle d'un Brownson et un agitateur sectaire comme Gavazzi.

Puis le procureur général prit la défense de l'inspecteur de police John Maguire, qui était devenu la cible d'attaques acharnées: le grave accident, dont le magistrat avait été victime dans l'accomplissement de son devoir, l'avait empêché de recourir subséquemment aux mesures qui s'imposaient. En revanche, lui-même, de concert avec le maire, il avait pourvu le soir précédent, alors que la rumeur circulait d'une agression possible contre l'hôtel, à la présence sur les lieux d'une force policière imposante; il avait même exhorté chaque occupant de l'hôtel à être armé pour faire feu sur la populace s'il y avait assaut contre l'édifice, après avertissement préalable donné d'une croisée de l'étage supérieur ${ }^{215}$. En effet, si grande était l'appréhension de la répétition contre l'hôtel Russell d'une entreprise semblable à celle qui avait fini en échauffourée à Chalmers' que le 71e régiment s'était tenu, durant toute la nuit du 7 au 8 juin, prêt à intervenir ${ }^{216}$.

Le conseil municipal, de son côté, ne négligeait rien pour délimiter la responsabilité de ceux qui eussent dû prévenir l'agitation du 6 juin et qui, de ce chef, subissaient le feu des critiques provenant surtout du comité présidé par John Cook. Dès le 7 , le maire requit les témoignages du constable en chef R. H. Russell et du juge de paix Robert Symes. Le premier avoua qu'il avait négligé de lui faire part ainsi qu'à l'inspecteur de police des bruits qui circulaient en ville dans l'après-midi du 6 juin. De même Symes dut admettre qu'il avait reçu dans le courant du même après-midi des déclarations assermentées

214 Cf. R. Sylvain, loc. cit., mai 1957, 774-775; septembre 1957, 30-40. 215 The Morning Chronicle, June 10, 1853.

216 The New York Express, June 11, 1853. 
au sujet d'une agitation possible, mais que, à son tour, il n'avait donné connaissance de ces déclarations ni au maire ni à Maguire ${ }^{217}$.

Touchant ce dernier, une enquête conduite par deux juges de paix protestants aboutit aux conclusions suivantes: $1^{\circ}$ le magistrat avait rempli son devoir lors du discours de Gavazzi au temple méthodiste, le samedi 4 juin, et avait en la circonstance pris les mesures nécessaires pour prévenir et dissiper toute agitation; $2^{\circ}$ Russell et Symes s'étaient rendus coupables d'un délit grave en lui dérobant ainsi qu'au maire les renseignements qu'ils avaient recueillis concernant l'émeute probable à Chalmers'; $3^{\circ}$ Maguire, aussitôt qu'il avait été mis au courant de l'agitation, s'était rendu rue Sainte-Ursule, où il avait donné ses ordres à la police; il n'avait été empêché d'accomplir son devoir jusqu'au bout que par l'accident qui l'avait immobilisé.

Le Journal de Québec, après avoir reproduit ces conclusions, ajoutait: «Les journaux protestants ont crié, protesté, menacé, remué ciel et terre parce que le gouvernement n'a pas démis M. Maguire sur le simple énoncé d'accusations dénuées de preuves. Aussi quels torrents d'invectives, d'injures, les saints du comité protestant ont-ils fait vomir par leurs dignes organes contre les papistes, le papisme, l'intolérance des romanistes, contre l'administration sur le cou de laquelle la prostituée de Babylone avait posé le joug (...) dans le dessein de perdre M. Maguire, dont le seul crime est d'être catholique romain, et d'exercer sur un seul la vengeance qu'ils ne pouvaient assouvir contre les papistes en masse ${ }^{218}$.»

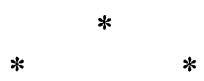

Maguire étant innocent, les auteurs de l'échauffourée ne l'étaient sûrement pas. Mais qui étaient-ils ? On avait aussitôt

217 Déposition de Tessier, Rapport, 49.

218 Journal de Québec, 25 octobre 1853. - L'édifice occupé par The Quebec Mercury, l'organe du «comité protestant», se trouvait au numéro 20 de la rue Buade, tandis que celui du Journal de Québec était au 26 de la même rue: le proche voisinage n'atténuait donc en rien, au contraire avivait peut-être, à cette époque de luttes idéologiques sans merci, l'opposition irréductible des attitudes! 
arrêté une dizaine d'individus; or le Grand Jury de la Cour du banc de la reine ne retint comme fondées, le 26 septembre 1853, que les accusations portées contre John Hearn, épicier au 293 Champlain, John Giblin, également épicier au numéro 68 de la même rue, Martin O'Brien, cordonnier dans la même rue, numéro 255, John Donoghue, au domicile inconnu, Hugh Gallagher, peintre-vitrier habitant la rue Saint-Paul, et Thomas Burns, tonnelier résidant au numéro 13 de la ruelle Sault-aumatelot ${ }^{219}$.

Les Irlandais n'avaient pas attendu que ces arrestations eussent lieu pour se concerter en vue de défendre leurs compatriotes, d'autant plus que le «comité protestant» suscitait les occasions de les harceler, par exemple lorsqu'il offrit une montre en or et une Bible au sergent Lawson ${ }^{220}$ et une bourse de vingt-cinq louis à John Mainhood, ancien policier londonien, qui se retirait de la police québécoise à laquelle il appartenait depuis deux ans: le récent événement, qui avait mis à nu l'inertie partisane de certains agents, l'avait à tout jamais «dégoûté de la conduite »de cette police ${ }^{221}$. Le dimanche 25 juin, à la fin de la messe dominicale, dans la cour attenant à l'église de St. Patrick, une assemblée se réunit pour «délibérer sur les moyens propres à assurer aux Irlandais catholiques accusés d'être les auteurs de l'émeute du temple de Chalmers un procès impartial et des moyens de défense ».

Il y fut résolu «que les représentations de la presse et l'intolérance importune de certaines personnes en cette cité s'ap-

219 Pays, 29 septembre 1853; adresses dans le Mackay's Quebec Directory ... 1852 et le McLaughlin's Quebec Directory ... for 1855-6. - Il est donc clair qu'aucun Canadien français ne participa à l'affaire, comme d'ailleurs Gavazzi lui-même l'admit dès son retour à New York (Cf. J. W. King, op. cit., 80). Si le plus récent biographe de l'ex-barnabite, le pasteur vaudois Luigi Santini, avait tenu compte de ce témoignage et s'il avait été averti du contexte social québécois au milieu du siècle dernier, il n'aurait certes pas écrit que « a Quebec (...) durante una predica (di Gavazzi) gli irlandesi, appogiati dall'elemento locale franco-canadese, provocarono una zuffa trasformatasi ben presto in battaglia 》. (Alessandro Gavazzi (Aspetti del problema religioso del Risorgimento), (Modène, 1955), 117).

220 The Quebec Gazette, June 15, 1853. - Avec l'inscription suivante: « Presented by Members of the Parliament of Canada to Sergeant W. G. Lawson, R.A., the Heroic Defender of Padre Gavazzi at the Riot in Chalmers' Church. Quebec, 6th June, 1853. 》

221 Déposition de Mainhood, Rapport, 74-75. 
pelant le «comité protestant»a recueilli de l'argent et retenu un conseil pour assister les officiers de la couronne dans la poursuite de personnes accusées de l'émeute en question, et en a fait, par tous les moyens en son pouvoir, une question à la fois religieuse et nationale, il est du devoir de cette assemblée de nommer un «comité de vigilance », afin d'assurer aux accusés un procès impartial et qu'aucune influence mauvaise ne soit employée à pervertir les fins de la justice ${ }^{222}$ ».

Entre-temps, jusqu'à ce que le procès eût lieu, la tension augmentait entre les deux groupes ethniques québécois. Il se fonda un journal publié trois fois la semaine, The Protestant Times ${ }^{223}$. The Father Gavazzi's Lectures and Life étaient en vente chez les libraires Sinclair \& Coombe, 56 rue Saint-Jean ${ }^{224}$. Les débris qui subsistaient de la bagarre, les fragments de la chaise qui s'était brisée dans les mains de Gavazzi, les morceaux de verre provenant des fenêtres fracassées par les cailloux des assiégeants, étaient recueillis avec soin et conservés précieusement, si du moins l'on en croit la lettre de l'un des The Gavazzi Guards insérée dans une publication orangiste ${ }^{225}$. Pour apaiser au moins momentanément l'irritation protestante, le conseil municipal vota une indemnité à James Gibb, propriétaire du temple de Chalmers ${ }^{226}$.

Mais en dépit de toutes les manœuvres adverses, les agitateurs, impliqués dans le mémorable événement du 6 juin, furent acquittés le 27 janvier 1854, faute de preuves décisives ${ }^{227}$. Seul le corps municipal de police, parce qu'il n'avait «pas fait son devoir», fut tenu responsable de l'échauffourée ${ }^{228}$.

222 Journal de Québec, 27 juin 1853.

223 The Montreal Gazette, August 3, 1853.

224 The Quebec Gazette, July 4, 1853. - In-12 de XI-299 pp. édité à New York par De Witt \& Davenport. Cette édition ne fut pas reconnue par Gavazzi comme reflétant fidèlement sa pensée (Cf. R. Sylvain, A. G. à New York, RHAF, XI (Juin 1957) : 82).

225 The Orange Lily and Ottawa Advocate, June 21, 1853. Lettre datée de «Quebec, June 13, 1853 ».

226 The Montreal Transcript, September 20, 1853.

227 Pays, 31 janvier 1854.

228 Rapport des commissaires, 14. 
La nécessité de marquer, pour n'y plus revenir, les conséquences qui découlèrent directement de cette flambée de haine raciale et religieuse, nous a entraîné bien au-delà du départ pour Montréal de Gavazzi. Le lendemain du jour où il avait failli perdre la vie aux mains des Irlandais de Québec, l'orateur se tint coi dans sa chambre de l'hôtel Russell. Le soir venu, par mesure de prudence, il quitta furtivement l'hôtel afin de passer la nuit dans une maison privée ${ }^{229}$, où il rédigea une longue lettre destinée à l'Eco d'Italia. Le 8 juin, défiant leurs adversaires, les protestants songèrent à le prier de prononcer une troisième causerie ${ }^{230}$. Mais le maire leur écrivit sans tarder que «dans le malheureux état de l'opinion publique surexcitée, les autorités municipales ne pouvaient pas se tenir responsables des conséquences de cette conférence ${ }^{231}$. Il ne restait donc plus à l'Italien qu'à quitter une ville où ses diatribes avaient provoqué une telle effervescence.

Le soir du 8 juin, avec Paoli que l'on transporta sur une civière ${ }^{232}$, il s'embarqua sur le vapeur Québec. Une cinquantaine d'orangistes, armés jusqu'aux dents, au témoignage d'un journaliste ${ }^{233}$, s'étaient constitués bénévolement sa garde personnelle pour le protéger durant son voyage ${ }^{234}$. Le maire avait requis à l'embarcadère un fort détachement de police, afin de prévenir toute récidive d'assaut sur la personne de celui qui était devenu un violent signe de contradiction pour les Québécois. Un nombre considérable de protestants avaient dévalé à la basseville pour acclamer une dernière fois leur héros. C'est à ce moment que jaillit de la foule, lancé par l'un des spectateurs qui fut immédiatement arrêté, un lourd ciseau de menuisier destiné à l'ex-barnabite, qui heureusement esquiva le projectile meurtrier ${ }^{235}$.

Gavazzi n'avait pas encore débarqué à Montréal que déjà la fièvre y montait. Les habitants du fief irlandais, Griffintown,

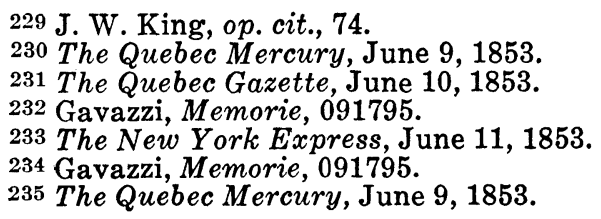


commençaient à bouger, alertés par les journaux montréalais qui avaient relaté en détail les événements survenus dans la capitale. John Dougall, cet Écossais qui depuis 1850 surtout marchait sur les brisées de cet autre Écossais qui s'appelait George Brown ${ }^{236}$ et dont le journal The Montreal Witness s'alignait en quelque sorte sur l'attitude anticatholique et anti-irlandaise des Know-Nothings ${ }^{237}$, publiait, le 8 juin, une édition supplémentaire de sa feuille: se détachait en pleine page un portrait en pied de Gavazzi revêtu de son costume monacal, la poitrine et l'épaule gauche ornées de l'inévitable croix tricolore, l'index dénonciateur prolongeant le bras droit levé en geste d'anathème ${ }^{238}$; l'article circonstancié du Quebec Chronicle du jour précédent, qui peignait les protestants rassemblés dans Chalmers' Church à la merci de la sauvagerie irlandaise, était reproduit in extenso; enfin Dougall avait inséré des extraits d'une lettre venant d'un ami québécois, dont la plume, pour être digne du moment, ne faisait allusion à rien de moins qu'aux épreuves eschatologiques de l'Apocalypse: «La lutte décisive va bientôt se livrer. Puisse Dieu nous donner à tous la grâce et la force de rester fermes dans les jours mauvais ${ }^{239}$. » Étaitil donc écrit que l'antique Ville-Marie assisterait sous peu à la résurgence en terre canadienne de la Saint-Barthélemy ?

Robert Sylvain, é.c., professeur à l'Institut d'histoire, Université Laval. 880-881.

236 Cf. R. Sylvain, Un «quarante-huitard»..., RUL, XI (Juin 1957) :

237 George Rex Crowley Keep, The Irish Migration to Montreal, 18471867 , thèse dactylographiée, McGill, 1948, 62.

${ }_{238} \mathrm{La}$ même gravure reparut dans l'Eco d'Italia, 18 giugno 1853 , accompagnée de la légende suivante:

«Il Crociato d'Italia !

Attentato d'assassinio contro Gavazzi !

Sommosse di Quebec e Montreal!

239 Montreal Witness Extra, June 8, 1853.

Guerra Santa nel Canadà !» 